\title{
Energy structure, digital economy, and carbon emissions: evidence from China
}

\author{
Yan $\mathrm{Li}^{1} \cdot$ Xiaodong Yang ${ }^{1} \cdot$ Qiying Ran ${ }^{1,2} \cdot$ Haitao $\mathrm{Wu}^{3,4} \cdot$ Muhammad Irfan $^{3,4} \cdot$ Munir Ahmad $^{5}$
}

Received: 26 April 2021 / Accepted: 1 July 2021 / Published online: 27 July 2021

(C) The Author(s), under exclusive licence to Springer-Verlag GmbH Germany, part of Springer Nature 2021

\begin{abstract}
As a new production factor, digitalization plays a vital role in society, economy, and the environment. Based on the expanded STIRPAT model, this paper empirically tests the impact of energy structure and digital economy on carbon emissions by panel data from 2011 to 2017 in 30 provinces of China. The results show that the energy structure mainly based on coal has a significant driving effect on carbon emissions. Compared with non-resource-based provinces, the increase of energy structure dominated by coal has a greater effect on carbon emission in resource-based provinces. It is worth noting that this kind of influence has a greater impact on the central region of China, followed by the western region and the eastern region. Besides, the digital economy has a significant moderating effect. With the development of digital economy, the impact of coal-based energy structure on carbon emissions is gradually decreasing. This effect is more significant in non-resource-based provinces and eastern China, but not significant in resource-based cities and central and western China.
\end{abstract}

Keywords Energy structure $\cdot$ Digital economy $\cdot$ Carbon emissions $\cdot$ Resource-based province

\section{Introduction}

In the past 40 years, China has not only experienced rapid economic growth, but also experienced a sharp rise in energy consumption and carbon emissions (Irfan et al. 2021). China has become the largest carbon emitter in the world (Wang et al. 2021). To actively tackle global climate change, the Chinese government has set a series of emission reduction targets. In 2015, when China submitted its Nationally Determined Contribution Document (INDC) to the United Nations to fight climate change, it announced: China would peak carbon dioxide emissions before 2030 and reduce its
Responsible Editor: Ilhan Ozturk

Qiying Ran

ranqyxjedu@126.com

Haitao Wu

haitao.kungfuer@gmail.com

Yan Li

1029868528@qq.com

Xiaodong Yang

yxdlovezt@126.com

Muhammad Irfan

irfansahar2010@gmail.com

Munir Ahmad

munirahmad@zju.edu.cn
1 School of Economics and Management, Xinjiang University, Urumqi 830047, China

2 Center of Innovation Management Research of Xinjiang, Xinjiang University, Urumqi 830047, China

3 School of Management and Economics, Beijing Institute of Technology, Beijing 100081, China

4 Center for Energy and Environmental Policy Research, Beijing Institute of Technology, Beijing 100081, China

5 School of Economics, Zhejiang University, Hangzhou 310058, China 
$\mathrm{CO}_{2}$ intensity by $60-65 \%$ from the 2005 level $^{1}$. At the 2020 Climate Ambition Summit, China further announced that by 2030 , its carbon intensity would be reduced by more than $65 \%$ compared with $2005^{2}$. To achieve these goals, China has taken a series of emission reduction measures but still faces great pressure on carbon emission reduction. At present, China's economic development is still highly related to coal consumption. According to China Energy Development Report 2018, China's total energy consumption has reached 4.64 billion tons of standard coal, 8.12 times of 1978. Among them, the proportion of coal consumption with high-carbon emission is as high as $59 \%$, far exceeding the world average consumption level of $30 \%$, while the proportion of energy consumption with low-carbon emission is far lower than the average level of developed countries (Yang and Wei 2018). According to the data of the National Bureau of Statistics, the change trend of energy consumption structure dominated by coal and carbon emissions from 2004 to 2017 is basically consistent (see Fig. 1); unreasonable energy structure will bring great harm to the ecological environment and people's physical and mental health, and pose a potential threat to the sustainable development of China's economy. In the critical period of economic transformation from high-speed growth to high-quality development, the optimization and adjustment of energy structure are important forces to promote "carbon peak and carbon emission reduction" (Yong and Ying 2019). Deeply exploring the differences in China's regional energy structure and clarifying its internal driving factors can provide a theoretical basis for the scientific formulation of differentiated emission reduction strategies. It is of great significance for China to achieve sustainable economic development and effectively deal with climate change.

In the new round of global technological and industrial change, the popularization of information technology has an important marginal utility (Vu 2011; Anser et al. 2021). The digital economy is taking information technology as the core to provide new impetus for the intelligent management of the environment (Kjaer et al. 2018; Usman et al. 2021). The generalized penetration and popularization of the digital economy in the fields of energy consumption and environmental protection are conducive to solving problems such as the decline in environmental carrying capacity and scarcity (Junior et al. 2018; Rehman et al. 2021a), and it has great potential for improving the ecological environment (Kjaer et al. 2018; Alam and Murad 2020). According to China Energy Statistical Yearbook, in 2017, China's per capita energy consumption and per capita electricity consumption were $32.79 \%$ and $37.17 \%$ of those of the USA, respectively. It is foreseeable that China's economy will continue to grow steadily. Economic growth means the increase of energy demand and China's energy consumption will continue to grow. China's

\footnotetext{
${ }^{1}$ See more details: www.gov.cn/guowuyuan/2015-06/30/content_2887287. htm.

${ }^{2}$ See more details: www.gov.cn/xinwen/2020-12/22/content 5572019.htm.
}

carbon emission reduction target is undoubtedly facing significant pressure and challenges. At the same time, global warming caused by carbon emissions will pose a considerable threat to public health and welfare in all countries (Watts et al. 2021; Shuai et al. 2017). As the digital economy has become an important starting point for high-quality economic development and the urgent requirements for climate change to take action, exploring the contribution of digital technology to energy conservation and emission reduction and the causes of regional differentiation can provide theoretical support for reasonably expanding the development level of digital economy, narrowing the development gap between regions, improving the emission reduction capacity of digital economy, and realizing the win-win development of "economic development-environmental optimization" for all countries..

In summary, the contribution of this paper has three aspects. First of all, in terms of digital economy indicators, on the basis of accurately understanding the connotation of digital economy, from a multi-dimensional and multi-level perspective, taking the Internet as the core, this paper uses entropy method to build a comprehensive digital economy index to comprehensively and systematically measure the development level of digital economy in each province from 2011 to 2017. Secondly, considering the great differences of economic development level and resource endowment among provinces in China, this paper explores the regional heterogeneity characteristics of the impact of energy structure on carbon emissions based on the above perspectives and analyzes the reasons for the heterogeneity. According to the characteristics of factor resource endowment of each region, we put forward targeted policy recommendations. In addition, combined with the background of the rapid development of the new generation of information technology revolution, this paper puts the digital economy, energy structure, and carbon emissions into a unified analysis framework, which provides a new perspective for reducing regional carbon emissions.

The rest of this paper is organized as follows: Sect. 2 summarizes the literatures and puts forward the research hypotheses; Sect. 3 briefly introduces the models and data used in this study; Sect. 4 provides empirical results of the study; in Sect. 5, results have been reported; Sect. 6 elaborates the conclusions and policy recommendations of this study.

\section{Literature review and research hypotheses}

\section{Energy structure and carbon emissions}

At present, there is a vast literature on the influencing factors of carbon emissions, but this paper is mostly concerned about the literature related to energy structure and carbon emissions (Ozturk and Acaravci 2010). Based on the data of OECD countries from 1980 to 2011, Shafiei and Salim (2014) found 
Fig. 1 Changes in energy structure and carbon emissions from 2004 to 2017. Note: Data collected from China Energy Statistical Yearbook from 2005 to 2018 , The dotted line is the trend line of the energy structure during the study period, reflecting the changing trend of the energy structure

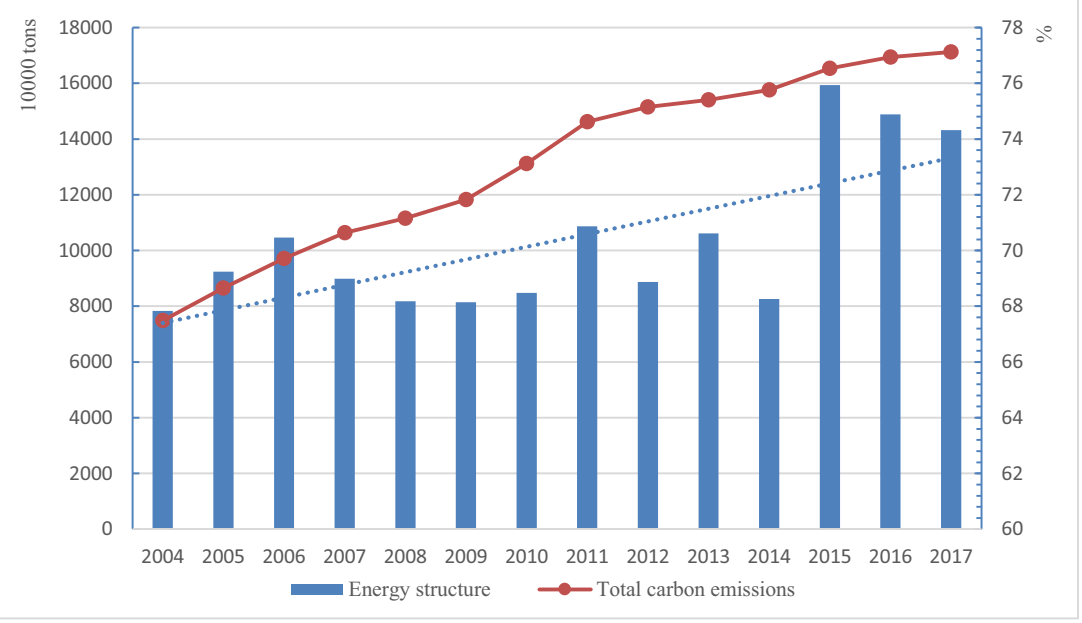

that the consumption of non-renewable energy increased carbon dioxide emissions, while the consumption of renewable energy reduced carbon dioxide emissions. The research of Dogan and Seker (2016) also reached the same result as theirs. Furthermore, Dogan and Seker (2016) believed that there was a two-way causality between renewable energy and carbon dioxide emissions. Then, whether the domestic energy consumption structure and carbon emissions also exist the abovementioned relationship. Most domestic scholars believe that the energy consumption structure is an important leading and restrictive factor affecting regional carbon emissions ( $\mathrm{Yu}$ et al. 2018; Rehman et al. 2020), and the change direction of the energy structure varies from province to province, resulting in a "high-carbon" situation and a "low-carbon" situation (Guozhi et al. 2011). Energy structure transformation and energy efficiency improvement are effective ways to reduce carbon emissions (Palencia et al. 2013; Ahmad et al. 2021), which can promote China's clean and low-carbon development (Wu et al., 2021). However, Xu et al. (2019) believe that the carbon emission reduction of clean energy will be offset because the scale of domestic clean energy consumption is far smaller than that of traditional fossil energy consumption, resulting in that the development of clean energy does not significantly reduce carbon dioxide emissions; further regional heterogeneity analysis shows that clean energy and carbon dioxide emissions in eastern China are "M-type", while clean energy and carbon dioxide emissions in central and western China are "U-type". Narayan and Doytch (2017) showed that the exogenous negative effect of low-carbon clean energy on economic growth might be more significant than its endogenous positive effect (Nguyen and Kakinaka 2019). Chen et al. (2020) further show that the promotion of renewable energy on economic growth is only established when the use of renewable energy exceeds a certain threshold.

Because China has a large geographical range from east to west, and its population characteristics, technological development level, and natural resources are different (Ahmad et al.
2019; Feng et al. 2021a), we cannot help thinking whether there are regional characteristics of carbon emissions in China. Therefore, according to the 2004-2017 China Energy Statistical Yearbook, we calculated the average carbon emissions and the overall carbon emission growth rate of nine major energy sources in 30 provinces of China. As shown in Table 1, from the average carbon emissions of 30 provinces (cities and autonomous regions), it can be seen that among the top ten provinces with the highest carbon emissions, the eastern provinces account for six, which are Shandong, Jiangsu, Guangdong, Hebei, Liaoning, and Zhejiang. The central provinces are Henan, Shanxi, and Hubei. Only Inner Mongolia is in the west. It can be seen that carbon emissions are unevenly distributed among regions. From the perspective of carbon sources that cause carbon emissions, coal and electricity consumption contribute the most to carbon emissions, indicating that China needs to transform its energy consumption structure. Besides, these ten provinces are basically China's major industrial provinces and resource-rich provinces, indicating carbon emissions endogenous to the current economic development model and resource endowment, the existence of differences in the level of economic development, and resource endowment has also caused the alienation of carbon emissions.

It is worth noting that from the perspective of the average growth rate of carbon emissions, the average growth rate of Hainan, Xinjiang, Guangxi, Ningxia, and Inner Mongolia all exceeded $10 \%$ from 2004 to 2017, and the average GDP growth rates of the other four provinces except Inner Mongolia were less than that of carbon emissions. Therefore, the quality of economic development at the expense of the environment is not high. On the contrary, the average carbon emission growth rate of Beijing, Guizhou, and Shanghai is less than $3 \%$, which is much lower than their average GDP growth rate, which has achieved a relative decoupling of economic development and carbon emissions. 
Table 1 China's average energy carbon emissions and average growth rate of carbon emissions from 2004 to 2017

Unit: 10,000 tons

\begin{tabular}{|c|c|c|c|c|c|c|c|c|c|c|}
\hline Region & Coal & Coke & Crude oil & Fuel oil & Gasoline & Kerosene & Diesel & Natural gas & Electric power & Average growth rate \\
\hline Beijing & 1182.08 & 17.95 & 804.75 & 33.99 & 301.52 & 198.07 & 167.53 & 511.92 & 2189.35 & $2.02 \%$ \\
\hline Tianjin & 2344.15 & 80.61 & 1066.11 & 86.74 & 160.94 & 18.88 & 270.23 & 197.79 & 1783.20 & $4.26 \%$ \\
\hline Hebei & $14,112.06$ & 743.69 & 1152.49 & 42.93 & 251.04 & 5.69 & 557.25 & 225.53 & 6995.37 & $5.26 \%$ \\
\hline Shanxi & $17,183.22$ & 262.38 & 0.00 & 6.23 & 159.04 & 8.60 & 376.79 & 188.22 & 4018.32 & $5.34 \%$ \\
\hline Inner Mongolia & $15,026.41$ & 148.97 & 198.24 & 13.07 & 221.49 & 8.27 & 514.33 & 202.01 & 4565.00 & $10.35 \%$ \\
\hline Liaoning & 8611.53 & 294.93 & 5230.38 & 273.02 & 468.21 & 15.06 & 750.54 & 231.12 & 4533.03 & $3.80 \%$ \\
\hline Jilin & 4746.50 & 58.21 & 806.65 & 33.03 & 133.18 & 3.07 & 282.52 & 99.86 & 1545.99 & $3.95 \%$ \\
\hline Heilongjiang & 6301.12 & 24.95 & 1686.10 & 71.06 & 280.02 & 18.35 & 415.85 & 187.53 & 2033.23 & $4.19 \%$ \\
\hline Shanghai & 2815.49 & 72.18 & 1795.10 & 600.71 & 358.34 & 193.77 & 414.71 & 296.17 & 3350.24 & $2.63 \%$ \\
\hline Jiangsu & $12,437.18$ & 291.32 & 2491.73 & 170.62 & 597.48 & 24.04 & 605.55 & 564.15 & $10,610.31$ & $7.11 \%$ \\
\hline Zhejiang & 6936.05 & 41.56 & 2114.52 & 274.76 & 475.89 & 37.87 & 764.42 & 256.18 & 7647.70 & $5.83 \%$ \\
\hline Anhui & 6861.57 & 99.52 & 421.99 & 14.02 & 196.38 & 5.72 & 372.00 & 111.54 & 3175.25 & $7.13 \%$ \\
\hline Fujian & 3670.14 & 57.92 & 901.28 & 145.72 & 278.37 & 35.41 & 387.43 & 153.35 & 3802.84 & $7.83 \%$ \\
\hline Jiangxi & 3296.34 & 78.82 & 407.37 & 22.04 & 134.55 & 3.06 & 341.80 & 49.77 & 2088.53 & $6.83 \%$ \\
\hline Shandong & $18,683.73$ & 325.13 & 5107.87 & 1471.83 & 527.03 & 23.66 & 1122.66 & 328.87 & 9639.28 & $8.26 \%$ \\
\hline Henan & $14,300.04$ & 210.10 & 660.92 & 45.71 & 322.80 & 19.68 & 521.42 & 338.58 & 6720.66 & $7.31 \%$ \\
\hline Hubei & 7539.79 & 106.03 & 861.68 & 102.88 & 454.48 & 26.49 & 596.78 & 141.90 & 3841.73 & $7.95 \%$ \\
\hline Hunan & 5688.84 & 103.74 & 614.77 & 56.36 & 287.74 & 16.72 & 425.52 & 86.84 & 3434.94 & $6.00 \%$ \\
\hline Guangdong & 7252.41 & 56.36 & 3293.54 & 740.83 & 847.91 & 109.14 & 1291.67 & 557.65 & $11,317.25$ & $5.14 \%$ \\
\hline Guangxi & 4197.74 & 81.62 & 625.85 & 24.00 & 196.41 & 11.74 & 374.23 & 26.19 & 2662.23 & $11.78 \%$ \\
\hline Hainan & 998.19 & 0.62 & 623.82 & 23.08 & 49.60 & 41.51 & 90.02 & 209.72 & 486.26 & $17.56 \%$ \\
\hline Chongqing & 2417.10 & 36.45 & 0.40 & 8.22 & 109.73 & 22.90 & 298.41 & 367.75 & 1746.48 & $3.45 \%$ \\
\hline Sichuan & 5106.13 & 150.29 & 376.56 & 58.45 & 475.27 & 95.49 & 491.27 & 839.83 & 4349.72 & $3.74 \%$ \\
\hline Guizhou & 5501.45 & 40.12 & 0.00 & 8.05 & 140.35 & 8.04 & 256.17 & 47.17 & 2456.13 & $2.55 \%$ \\
\hline Yunnan & 5015.16 & 128.99 & 0.04 & 3.41 & 188.02 & 28.39 & 419.94 & 32.94 & 2867.72 & $7.31 \%$ \\
\hline Shaanxi & 6850.30 & 72.17 & 1537.92 & 8.96 & 194.40 & 12.05 & 360.31 & 357.39 & 2541.31 & $9.52 \%$ \\
\hline Gansu & 2884.52 & 60.70 & 1181.58 & 8.97 & 83.15 & 2.84 & 196.80 & 105.47 & 2252.96 & $4.97 \%$ \\
\hline Qinghai & 777.10 & 18.21 & 105.04 & 0.22 & 24.86 & 0.11 & 74.44 & 188.41 & 1272.90 & $8.56 \%$ \\
\hline Ningxia & 3452.07 & 31.49 & 252.96 & 24.68 & 19.93 & 1.38 & 87.81 & 89.62 & 1674.07 & $10.54 \%$ \\
\hline Xinjiang & 5602.51 & 69.58 & 1835.03 & 11.17 & 137.32 & 15.22 & 376.62 & 578.97 & 3004.25 & $12.80 \%$ \\
\hline
\end{tabular}

Data collected from China Energy Statistical Yearbook from 2005 to 2018

It implies that there are still some provinces with low energy efficiency in China.

Based on the above analysis, this paper proposes the first and second hypotheses as:

H1: The impact of energy structure on carbon emissions is regional heterogeneity due to different local development levels.

H2: The impact of energy structure on carbon emissions is regional heterogeneity due to the resource endowment gap.

\section{Energy structure, digital economy, and carbon emissions}

According to the estimation of the State Internet Information Office, the added value of China's digital economy accounts for $36.2 \%$ of GDP. There is no doubt that the digital economy is having an important impact on all aspects of our lives. Due to the short development time of digital economy, there are few literatures on digital economy and energy structure, digital economy, and carbon emissions. Miller and Wilsdon (2001) pointed out that digital economy represents a technological revolution and is the decisive factor of technological innovation. Digital technology has played a fundamental business change in the value chain of almost all industries (Yuan et al. 2021). The solutions of digital technology in energy, manufacturing, agriculture and land use, construction, services, transportation, and other fields can help reduce global carbon emissions by $15 \%$ (The Exponential Roadmap 2020). Among all industries, the energy sector is one of the fields with the largest 
emission reduction effect after the application of digital technology.

The impact of digital economy on the energy system is reflected in both supply and demand. On the supply side, digital technology monitors the data of the energy production link, prevents and warns production risks in advance, and improves the production efficiency of the traditional fossil energy industry. Thus, digital technology ensures the safe and efficient operation of the energy system (Chen 2020) and reduces the degree of damage to the environment (Soares and Tolmasquim 2000; Rademaeker et al. 2014). Alam and Murad (2020) found that improving the level of technology utilization can promote the development and utilization of renewable energy. Digital technology shortens the $R \& D$ cycle of clean energy and improves $R \& D$ efficiency through accurate 3D modeling of natural and geographical conditions (Allam and Jones 2021). Similar to traditional fossil energy, digital technology has been applied in the field of new energy. Such applications enable staff to perceive data more accurately, predict meteorological changes, and improve the utilization of clean energy. In addition, digital technology helps the government to control the total amount of energy supply through pricing and cross-subsidies (Bhattacharya et al. 2015), which in turn promotes the transformation of energy consumption structure and ultimately achieves effective carbon emission control. On the demand side, the application of digital technology in areas with self-diagnosis, satellite navigation, entertainment systems, and key infrastructure and transportation systems can improve the efficiency of energy sales and consumption in the whole society. The application of digital transportation platform in the fields of smart cars, housing, electrical appliances, and so on brings great significance to energy conservation (Aydin et al. 2018). The digital economy reduces the demand for energy and raw materials through the dematerialization of human activities and communication (Heiskanen et al. 2005). For example, during the COVID-19 outbreak, online office reduced public travel, and therefore, energy consumption reduced. Generally speaking, the digital economy "empowerment" effect is significant, and the information integration effect can weaken the information asymmetry between the supply and demand sides. The integration and penetration of the digital economy in the field of energy consumption will help to achieve the synchronous improvement of energy use efficiency between supply and demand, transform the consumption pattern, and effectively promote the development of a low-carbon economy.

Based on the above analysis, this paper proposes the third and fourth hypotheses as:

H3: Digital economy can weaken the negative effect of energy structure on carbon emissions.

H4: The impact of the digital economy on the energy structure and carbon dioxide emissions is heterogeneous.
Although many scholars have conducted a large number of normative and empirical studies on energy structure and carbon emissions, there are still some limitations to the research in this field. There is a growing body of relevant studies, but the latest data analysis of the relationship between the two is lacking. In addition, previous studies generally directly studied the relationship between energy structure and carbon emissions. Unfortunately, there is a lack of discussion on the relationship between energy structure and carbon emissions in the context of the digital economy. Obviously, the development of the digital economy will have a significant impact on the relationship between the two. What is more, although some literature has discussed the heterogeneity caused by regional development gaps, insufficient attention has been paid to the impact of resource endowment differences on the research results. Finally, the previous literature on energy structure and carbon emissions has carried out a linear analysis as a whole. The empirical results using the proportion of coal consumption as the proxy variable of the energy structure basically show that there is a positive correlation between the energy structure and carbon emissions, but in this paper, the empirical results show that the actual relationship between energy structure and carbon emissions may be nonlinear (Fig. 2).

\section{Model construction and variable selection}

\section{Model construction}

\section{Benchmark model}

Ehrlich and Holdren (1971) first proposed IPAT model as a framework to study the impact of population growth on the environment, and the specific model settings are as follows:

$C=P \cdot A \cdot T$

where, $C$ denotes carbon emissions, $P$ means population, $A$ means affluence, and $T$ means technology. However, the IPAT equation does not take into account the differences in the sensitivity of the dependent variables to the influencing factors and cannot observe the impact of factors other than population, affluence, and technology on environmental pressure. In order to overcome the limitations of this model, Dietz and Rosa (1994) established the stochastic form of IPATSTIRPAT model. In order to study the impact of energy structure on carbon emissions, following Ren et al. (2021) and adding energy structure (E) into model (1) to analyze the impact of energy structure on carbon emissions, the following model can be obtained:

Carbon emissions $=P_{i t} \cdot A_{i t} \cdot T_{i t} \cdot E_{i t}$. 
Fig. 2 Mechanism analysis diagram

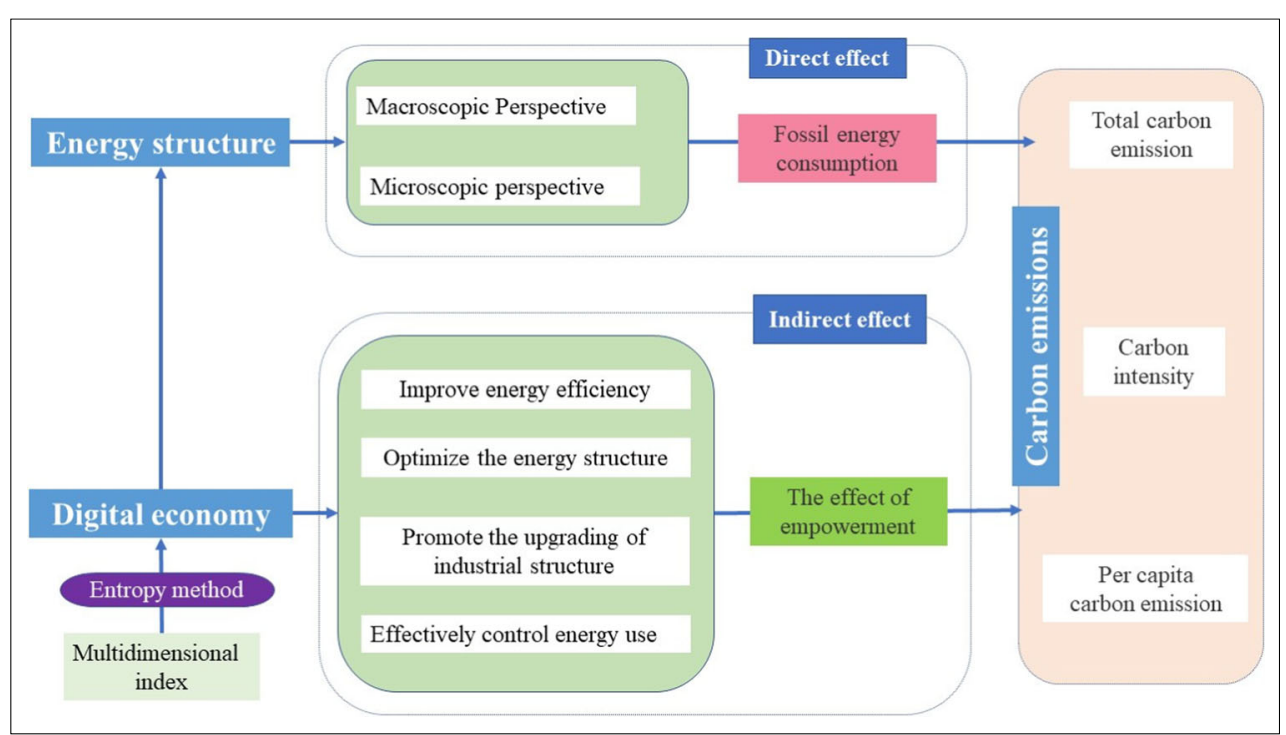

In addition, according to previous studies, carbon emissions are also affected by other variables. Therefore, this paper appropriately extends the STIRPAT model:

$C=P_{i t} \cdot A_{i t} \cdot T_{i t} \cdot E_{i t} \cdot$ other variables ${ }_{i t}$.

From the perspective of model and data processing, taking logarithm will not change the nature and correlation of the data but will compress the variable scale, make the data more stable, and weaken the collinearity and heteroscedasticity of the model. From the perspective of the research problem itself, we need to understand the impact of each unit change of influencing factors on carbon emissions. By taking logarithm, we can convert the multiplication in the model into addition. At this time, the regression coefficient can be explained by the concept of "elasticity" in economics, which is convenient for us to analyze the impact of various influencing factors on carbon emissions. Therefore, we take logarithm on both sides of model (3); the following equation can be obtained:

$$
\begin{aligned}
\ln C_{i t}= & \alpha_{0}+\alpha_{1} \ln P_{i t}+\alpha_{2} \ln A_{i t}+\alpha_{3} \ln T_{i t}+\alpha_{4} \ln E_{i t} \\
& +\alpha_{5} \ln X_{i t}+\varepsilon_{i t} .
\end{aligned}
$$

In the specific analysis, total carbon emissions $(T C)$, the carbon intensity $(C I)$, and per capita carbon emissions $(C P)$ are taken as the proxy variables of carbon emissions, and population size, per capita GDP, and energy intensity were taken as the proxy variables of population, affluence, and technology.

Because the early carbon emissions may have an impact on the current and future carbon emissions, and considering that the lag term is easily related to the residual term of the model, this paper introduces the lag term of carbon emissions into the model to build a dynamic panel model. The lagged term of carbon emissions included in the explanatory variables is often correlated with the unobservable cross-sectional heterogeneity effect. Due to the limited number of control variables added in the model, the important explanatory variables may be omitted, which will lead to the correlation between explanatory variables and error terms, resulting in the endogeneity of the model (Hsiao 1986) ${ }^{3}$. We use System GMM to estimate the model and Arellano bond test and Hansen test to verify the model.

\section{Moderation effect}

In order to test the moderating role of the digital economy in the impact of energy structure on carbon emissions, the following model is constructed, where $\mathrm{D}$ is the digital economy:

$$
\begin{aligned}
\ln C_{i t}= & \alpha_{0}+\alpha_{1} \ln P_{i t}+\alpha_{2} \ln A_{i t}+\alpha_{3} \ln T_{i t}+\alpha_{4} \ln E_{i t} \\
& +\alpha_{5} \ln D_{i t}+\alpha_{6} \ln E_{i t} \times \ln D_{i t}+\alpha_{7} \ln X_{i t}+\varepsilon_{i t} .
\end{aligned}
$$

The significance of the interaction coefficient can test whether the digital economy has a moderating effect on the impact of the energy structure on carbon emissions. When the interaction term between the energy structure and the digital economy and the original frequency term exists at the same time, the model regression results may be biased due to the

\footnotetext{
${ }^{3}$ In this regard, the current mainstream idea is to use dynamic GMM method. The dynamic GMM method is divided into System GMM and Difference GMM, and the Difference GMM destroys the integrity of sample information while removing the fixed effect, which leads to the problem of weak instrumental variables (Arellano and Bond 1991). The characteristic of System GMM is to estimate the horizontal equation and the difference equation at the same time. It can improve the real efficiency by adding the lag difference variable as the tool variable of the model and ensure the integrity of the sample information (Blundell and Bond 1998). Before using GMM model of dynamic panel system, two conditions should be satisfied: there is no sequence correlation in random error term, and there is no weak instrumental variable.
} 
existence of collinearity problems. Therefore, the interaction items in model (5) are centralized.

\section{Threshold effect}

According to the regression results of the moderating effect of the digital economy in the impact of energy structure on carbon emissions, it can be found that the moderating effect varies in different regions. Therefore, this paper conjectures that the moderating effect of the digital economy may have some nonlinear influence; that is, with the development level of the digital economy, the energy structure and carbon emissions show an inconsistent change. Referring to $\mathrm{Li}$ et al. (2021a), this paper constructs model (6):

$$
\begin{aligned}
\ln C_{i t}= & \alpha_{0}+\alpha_{1} \ln P_{i t}+\alpha_{2} \ln A_{i t}+\alpha_{3} \ln T_{i t}+\alpha_{4} \ln E_{i t} \\
& \cdot F\left(\ln D_{i t} \leq q\right)+\alpha_{5} \ln E_{i t} \cdot F\left(\ln D_{i t} \geq q\right)+\alpha_{6} \ln X_{i t} \\
& +\mu_{i}+\varepsilon_{i t}
\end{aligned}
$$

where: $F(*)$ is the indicator function, $q$ is the threshold value, and the other variables are consistent with the above.

\section{Variable selection}

Due to the serious lack of data of some three-level indicators of digital economy before 2011, in view of the availability and integrity of data of digital economy indicators, this paper only uses the data from 2004 to 2017 to make a preliminary analysis of the relationship between energy structure and carbon emissions. The empirical analysis uses the panel data of 30 provinces (excluding Tibet, Hong Kong, Macao, and Taiwan) from 2011 to 2017 according to the actual situation. The selection of variables and relevant data sources are as follows:

(1) Total carbon emissions. This paper draws on the ideas of Liu et al. (2021); the material balance algorithm is adopted to calculate the total carbon emissions according to formula (7):

$T C_{i t}=\sum_{m=1}^{9} E_{i t m} \times H_{m} \times D_{m}, \quad m \epsilon\{1,9\}$ where, $i$ is the province, $t$ is the year, and $M$ is the energy type. Energy consumption is represented by $E$, and the energy conversion coefficient and energy carbon emission coefficient are denoted by $H$ and $D$, respectively (see Table 2).

(2) The carbon emission intensity. The intensity of carbon dioxide emissions is the amount of $\mathrm{CO}_{2}$ emissions per unit of GDP, and the calculation formula is total carbon dioxide emissions/GDP (Liu et al. 2021).

(3) Per capita carbon emissions. Referring to Li et al. (2021a, 2021b), per capita carbon emissions are measured by the ratio of total carbon dioxide emissions to the total population. As we have analyzed, the regional heterogeneity characteristics of energy structure on carbon emissions in Sect. 2.1. In Sect. 3.2, we show the heterogeneity characteristics of carbon emissions and the current situation of energy structure more intuitively and vividly in the form of graphs (Figs. 3 and 4).

(4) Energy structure. As coal is the main source of energy consumption in China, compared with oil, natural gas, electric power, and other energy sources, coal contributes the most to China's economic growth (Bhattacharya et al. 2015). Therefore, the proportion of coal consumption in energy consumption is used to express the energy structure.

(5) Digital economy. A single index cannot comprehensively and accurately measure the real development level of the digital economy. Drawing on the ideas of Liu et al. (2020) , this paper uses the entropy method to construct the digital economy index with the internet as the core (Cao et al. 2021). The development level of digital economy of 30 provinces in 2011 and 2017 are shown in Fig. 5. By comparison, we can clearly see that the development speed of digital economy in eastern coastal areas is faster (Table 3).

(6) Control variables.

(1) Population. Population factor will affect greenhouse gas emissions through "total amount" and "speed" (Birdsall 1992). Knapp and Mookerjee (1996) believe that population is the reason for the growth of global $\mathrm{CO}_{2}$ emissions. As the number of permanent residents reflects the actual population of the region, we follow the method of Liu et al. (2021); the population is measured by the total resident population.

(2) Affluence. As a comprehensive measure of the production capacity of products and services within the region, GDP

Table 2 Energy conversion coefficient and energy carbon emission coefficient

\begin{tabular}{llllllllll}
\hline Energy types & Coal & Coke & Crude oil & Fuel oil & Gasoline & Kerosene & Diesel & Natural gas & Electric power \\
\hline $\mathrm{H}_{\mathrm{m}}$ & 0.7143 & 0.9714 & 1.4286 & 1.4286 & 1.4714 & 1.4714 & 1.4571 & 13.3 & $0.1229 \mathrm{~kg} \mathrm{standard} \mathrm{coal} / \mathrm{kWh}$ \\
$\mathrm{D}_{\mathrm{m}}$ & 0.7476 & 0.1128 & 0.5854 & 0.6176 & 0.5532 & 0.3416 & 0.5913 & 0.4479 & 2.2132 \\
\hline
\end{tabular}

Source: $\mathrm{H}_{\mathrm{m}}$ data from China Energy Statistical Yearbook 2018, $\mathrm{D}_{\mathrm{m}}$ data from IPCC 2006

According to China Energy Statistics Yearbook, nine kinds of energy include coal, coke, crude oil, fuel oil, gasoline, kerosene, diesel oil, natural gas, and electric power. 


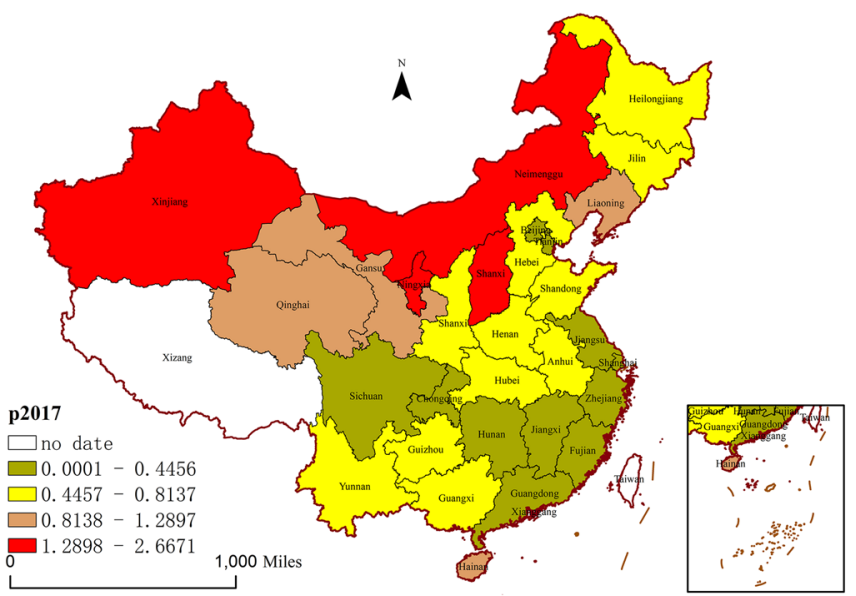

Carbon emission intensity in 2017

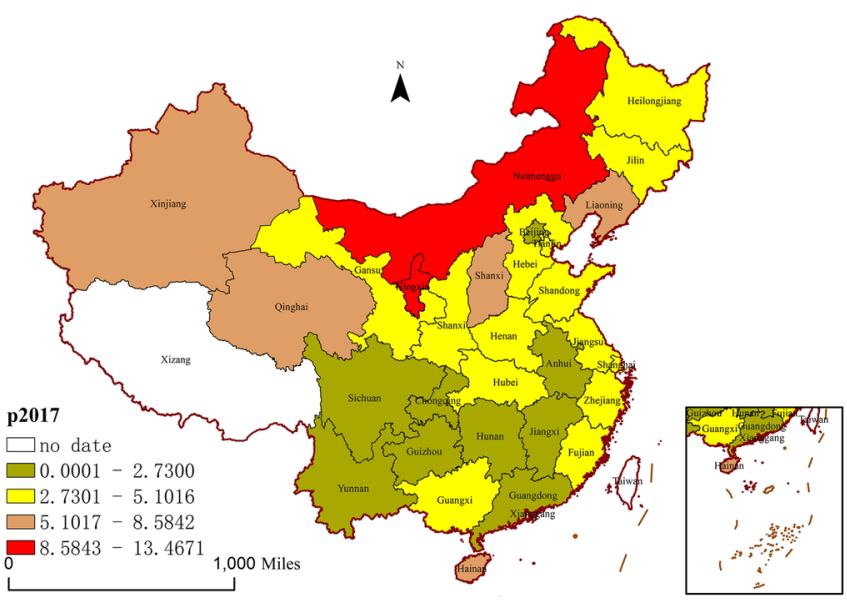

Carbon emissions per capita in 2017

Fig. 3 Carbon emissions and carbon emission intensity in China

per capita can well reflect the economic development stage and the material life prosperity of residents. Because the index has the characteristics of comparability, comprehensiveness, and ease of access, it can meet the research needs of this paper. Thus, the per capita GDP is regarded as the indicator of prosperity (Rehman et al. 2019).

(3) Technology. As a proxy variable of technology, energy intensity is a measure of energy efficiency. The higher the energy efficiency, the lower the energy intensity and the lower the carbon emissions (Cansino et al. 2015). Energy intensity is expressed as the proportion of total energy consumption in GDP (Liu et al. 2015).

(4) Research and development level. The increase in R\&D expenditure can improve the level of energy utilization, which is an important driving force of carbon emissions reduction (Petrović and Lobanov 2020). This paper uses R\&D spending as a share of GDP to represent R\&D levels.

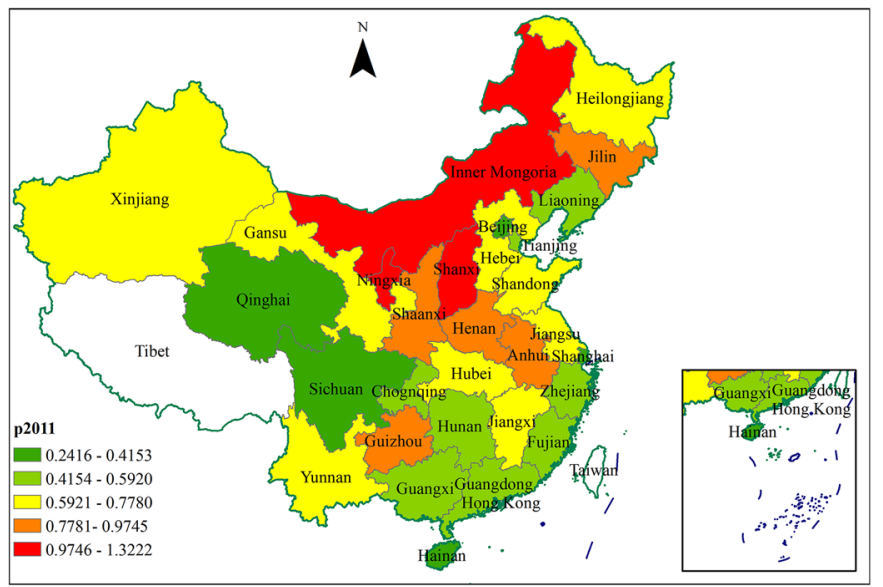

Energy structure in 2011
(5) Human capital level. The improvement of the human capital level is conducive to carbon emission reduction (Huang et al. 2021). The level of human capital is measured by urban per capita expenditure on education.

(6) Foreign direct investment. The impact of foreign direct investment on China's environmental pollution has always been two opposing hypotheses: "pollution paradise" and "pollution halo". This article draws on the selection of actual foreign direct investment as a percentage of GDP (Hao et al. 2021a; Su et al. 2021).

(7) Trade structure. Under the background of globalization, carbon emissions are transferred globally along with goods and services. The carbon emissions caused by global international trade have jumped from less than $20 \%$ in 1990 to more than $30 \%$ in 2010 in 20 years (Yan et al. 2020). Trade openness is measured by the ratio of total imports and exports to GDP (Ertugrul et al. 2016).

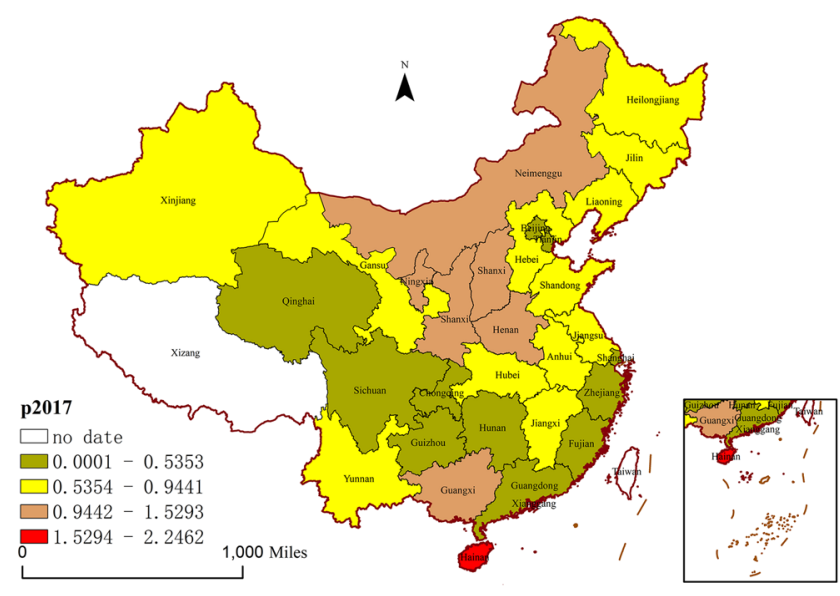

Energy structure in 2017

Fig. 4 Energy structure in China 


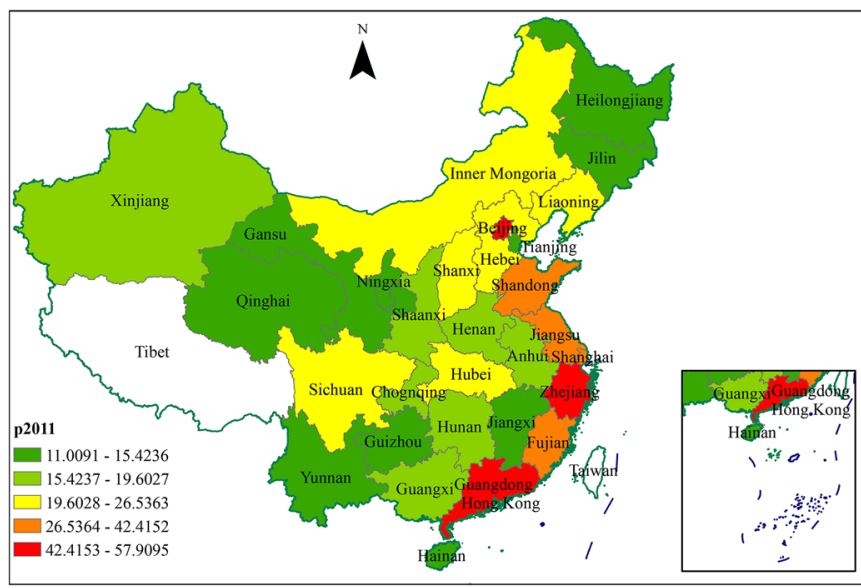

Digital economy in 2011

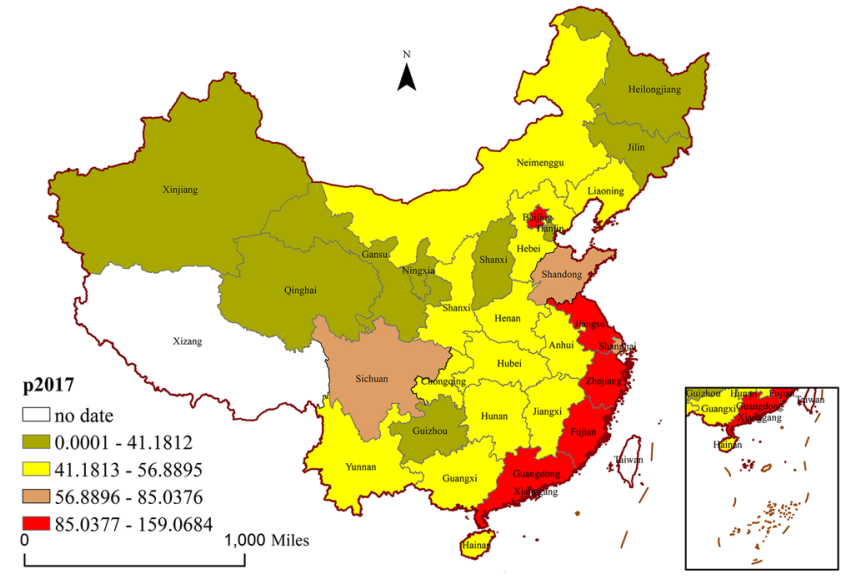

Digital economy in 2017

Fig. 5 Digital economy in China

(8) Industrial structure. Industrial development will cause environmental pollution and degradation (Antoci et al. 2018), and the rapid development of industrialization will bring great harm to the urban environment (Mahmood et al. 2020). Industrial structure is expressed as the proportion of industrial added value in GDP (Feng et al. 2021b).

(9) Social structure. Urban expansion derives a large amount of energy consumption demand and leads to a corresponding increase in pollutant emissions (Maheshwari et al. 2020; Zhang and Lin 2012). Referring to Gan et al. (2020), the proportion of the urban population in the total population of each region in each year is used as the proxy variable of urbanization level.
All variables in this paper were logarithmically processed, and the data came from China Statistical Yearbook and China Energy Statistical Yearbook (Table 4).

\section{Research results}

\section{Direct effects of energy structure on carbon emissions}

The Hausman test is performed on the extended STIRPAT model. The results show that the model should not ignore the province effect and time effect on carbon emissions. Therefore, the province effect and time effect are controlled in this paper. As can be seen from the regression results

Table 3 Comprehensive index system of digital economy development level

\begin{tabular}{|c|c|c|c|c|}
\hline Main indicator & First level indicator & Secondary indicator & Third level indicator & $\begin{array}{l}\text { Indicator } \\
\text { unit }\end{array}$ \\
\hline \multirow{14}{*}{$\begin{array}{l}\text { Digital economy } \\
\text { index }\end{array}$} & \multirow[t]{5}{*}{ Informatization development index } & \multirow[t]{3}{*}{ Information foundation } & Optical cable density & $\%$ \\
\hline & & & Density of mobile phone base station & $\%$ \\
\hline & & & Proportion of informatization employee & $\%$ \\
\hline & & \multirow[t]{2}{*}{ Impact of informatization } & Total telecom services & $\%$ \\
\hline & & & Software business revenue & $\%$ \\
\hline & \multirow[t]{4}{*}{ Internet development indicator } & Fixed end Internet foundation & Internet access port density & $\%$ \\
\hline & & Mobile Internet foundation & Mobile phone penetration & $\%$ \\
\hline & & Impact of fixed end Internet & Proportion of broadband Internet user & $\%$ \\
\hline & & Impact of mobile Internet & Proportion of mobile Internet user & $\%$ \\
\hline & \multirow{5}{*}{$\begin{array}{l}\text { Digital transaction development } \\
\text { indicator }\end{array}$} & \multirow{3}{*}{$\begin{array}{l}\text { Fundamentals of digital } \\
\text { trading }\end{array}$} & Proportion of enterprise website & $\%$ \\
\hline & & & $\begin{array}{l}\text { Proportion of computers used by } \\
\text { enterprise }\end{array}$ & $\%$ \\
\hline & & & Proportion of e-commerce & $\%$ \\
\hline & & \multirow[t]{2}{*}{ Impact of digital transactions } & E-commerce sale & $\%$ \\
\hline & & & Online retail sale & $\%$ \\
\hline
\end{tabular}


Table 4 Descriptive statistics

\begin{tabular}{lllllll}
\hline Variable & Variable & Obs & Mean & Std. dev. & Min & Max \\
\hline Total carbon emissions & C & 210 & $15,934.12$ & $10,176.96$ & 2246.95 & $52,335.68$ \\
Carbon emission intensity & CI & 210 & 0.91 & 0.57 & 0.20 & 3.13 \\
Carbon emissions per capita & CP & 210 & 4.09 & 2.42 & 1.37 & 13.47 \\
The energy structure & E & 210 & 0.72 & 0.37 & 0.05 & 2.32 \\
The digital economy & D & 210 & 41.53 & 28.60 & 11.01 & 175.01 \\
Population & P & 210 & 4534.60 & 2711.61 & 568.00 & $11,169.00$ \\
Affluence & A & 210 & 5.07 & 2.34 & 1.64 & 12.90 \\
Technology & T & 210 & 0.82 & 0.42 & 0.25 & 2.05 \\
R\&d spending & rd & 210 & 0.02 & 0.01 & 0.00 & 0.06 \\
Human capital & rlzb & 210 & 2218.72 & 721.44 & 967.90 & 5087.20 \\
Foreign direct investment & fdi & 210 & 0.33 & 0.33 & 0.05 & 1.76 \\
The trade structure & mykf & 210 & 0.28 & 0.32 & 0.02 & 1.55 \\
The industrial structure & ind & 210 & 0.45 & 0.08 & 0.19 & 0.59 \\
The social structure & csh & 210 & 0.57 & 0.12 & 0.35 & 0.90 \\
\hline
\end{tabular}

Table 5 Benchmark regression results

\begin{tabular}{|c|c|c|c|c|c|c|c|c|c|}
\hline \multirow[t]{2}{*}{ Explanatory variables } & \multicolumn{6}{|c|}{ Static panel model (OLS) } & \multicolumn{3}{|c|}{ Dynamic panel model (SYS-GMM) } \\
\hline & $\mathrm{TC}$ & $\mathrm{CI}$ & $\mathrm{CP}$ & $\mathrm{TC}$ & CI & $\mathrm{CP}$ & $\mathrm{TC}$ & CI & $\mathrm{CP}$ \\
\hline $\ln E$ & $\begin{array}{l}0.352^{* * * *} \\
(22.94)\end{array}$ & $\begin{array}{l}0.386 * * * * \\
(22.09)\end{array}$ & $\begin{array}{l}0.356^{* * * *} \\
(24.59)\end{array}$ & $\begin{array}{l}0.342^{* * * *} \\
(30.58)\end{array}$ & $\begin{array}{l}0.342^{* * * *} \\
(30.58)\end{array}$ & $\begin{array}{l}0.342^{* * * *} \\
(30.58)\end{array}$ & $\begin{array}{l}0.432^{* * * *} \\
(25.79)\end{array}$ & $\begin{array}{l}0.412^{* * * *} \\
(15.35)\end{array}$ & $\begin{array}{l}0.153^{\text {*** }} \\
(2.55)\end{array}$ \\
\hline $\ln P$ & & & & $\begin{array}{l}1.254^{\text {***** }} \\
(4.30)\end{array}$ & $\begin{array}{l}0.254 \\
(0.87)\end{array}$ & $\begin{array}{l}0.254 \\
(0.87)\end{array}$ & $\begin{array}{l}1.001^{* * * *} \\
(21.93)\end{array}$ & $\begin{array}{l}-0.001 \\
(-0.05)\end{array}$ & $\begin{array}{l}-0.043 \\
(-0.82)\end{array}$ \\
\hline $\ln A$ & & & & $\begin{array}{l}0.959^{* * * *} \\
(10.30)\end{array}$ & $\begin{array}{l}-0.041 \\
(-0.44)\end{array}$ & $\begin{array}{l}0.959^{* * * *} \\
(10.30)\end{array}$ & $\begin{array}{l}1.119^{* * * *} \\
(7.13)\end{array}$ & $\begin{array}{l}0.498^{* * * *} \\
(4.14)\end{array}$ & $\begin{array}{l}0.651^{* * *} \\
(2.18)\end{array}$ \\
\hline $\ln T$ & & & & $\begin{array}{l}0.784^{* * * *} \\
(11.38)\end{array}$ & $\begin{array}{l}0.784^{* * * *} \\
(11.38)\end{array}$ & $\begin{array}{l}0.784^{* * * *} \\
(11.38)\end{array}$ & $\begin{array}{l}0.974^{* * * *} \\
(8.30)\end{array}$ & $\begin{array}{l}0.949^{* * * *} \\
(15.68)\end{array}$ & $\begin{array}{l}0.492^{* * * *} \\
(3.67)\end{array}$ \\
\hline $\ln r d$ & & & & $\begin{array}{l}0.002 \\
(0.04)\end{array}$ & $\begin{array}{l}0.002 \\
(0.04)\end{array}$ & $\begin{array}{l}0.002 \\
(0.04)\end{array}$ & $\begin{array}{l}-0.088 \\
(-1.01)\end{array}$ & $\begin{array}{l}-0.175^{*} \\
(-1.65)\end{array}$ & $\begin{array}{l}0.184 \\
(0.99)\end{array}$ \\
\hline $\ln r l z b$ & & & & $\begin{array}{l}-0.097^{\text {**** }} \\
(-2.54)\end{array}$ & $\begin{array}{l}-0.097^{* *} \\
(-2.54)\end{array}$ & $\begin{array}{l}-0.097^{* * *} \\
(-2.54)\end{array}$ & $\begin{array}{l}-0.058 \\
(-1.51)\end{array}$ & $\begin{array}{l}-0.124^{* * * *} \\
(-4.09)\end{array}$ & $\begin{array}{l}-0.095 \\
(-1.28)\end{array}$ \\
\hline $\ln f d i$ & & & & $\begin{array}{l}-0.006 \\
(-0.35)\end{array}$ & $\begin{array}{l}-0.006 \\
(-0.35)\end{array}$ & $\begin{array}{l}-0.006 \\
(-0.35)\end{array}$ & $\begin{array}{l}-0.026 \\
(-0.78)\end{array}$ & $\begin{array}{l}-0.014 \\
(-0.63)\end{array}$ & $\begin{array}{l}-0.012 \\
(-0.37)\end{array}$ \\
\hline lnmykf & & & & $\begin{array}{l}0.014 \\
(0.93)\end{array}$ & $\begin{array}{l}0.014 \\
(0.93)\end{array}$ & $\begin{array}{l}0.014 \\
(0.93)\end{array}$ & $\begin{array}{l}0.141^{* * * *} \\
(3.37)\end{array}$ & $\begin{array}{l}0.051^{* * *} \\
(2.22)\end{array}$ & $\begin{array}{l}0.054 \\
(1.42)\end{array}$ \\
\hline lnind & & & & $\begin{array}{l}-0.036 \\
(-0.42)\end{array}$ & $\begin{array}{l}-0.036 \\
(-0.42)\end{array}$ & $\begin{array}{l}-0.036 \\
(-0.42)\end{array}$ & $\begin{array}{l}-0.636^{\text {**** }} \\
(-3.04)\end{array}$ & $\begin{array}{l}-0.307^{* * * *} \\
(-2.58)\end{array}$ & $\begin{array}{l}-0.563^{* *} \\
(-2.20)\end{array}$ \\
\hline $\operatorname{lncsh}$ & & & & $\begin{array}{l}-0.353^{* * *} \\
(-2.03)\end{array}$ & $\begin{array}{l}-0.353^{* *} \\
(-2.03)\end{array}$ & $\begin{array}{l}-0.353^{* *} \\
(-2.03)\end{array}$ & $\begin{array}{l}-0.119 \\
(-0.21)\end{array}$ & $\begin{array}{l}-0.453 \\
(-1.40)\end{array}$ & $\begin{array}{l}-0.975 \\
(-1.54)\end{array}$ \\
\hline L. $\ln C$ & & & & & & & $\begin{array}{l}0.037^{* *} \\
(2.44)\end{array}$ & & \\
\hline$L . \ln C I$ & & & & & & & & $\begin{array}{l}0.056^{* * * *} \\
(2.77)\end{array}$ & \\
\hline L. $\ln C P$ & & & & & & & & & $\begin{array}{l}0.649^{* * * *} \\
(5.33)\end{array}$ \\
\hline Constant & $\begin{array}{l}9.533^{* * * *} \\
(714.00)\end{array}$ & $\begin{array}{l}0.077^{* * * *} \\
(5.09)\end{array}$ & $\begin{array}{l}1.356^{* * * *} \\
(107.91)\end{array}$ & $\begin{array}{l}-1.393 \\
(-0.58)\end{array}$ & $\begin{array}{l}-1.393 \\
(-0.58)\end{array}$ & $\begin{array}{l}-1.393 \\
(-0.58)\end{array}$ & $\begin{array}{l}-0.628 \\
(-0.90)\end{array}$ & $\begin{array}{l}-0.762 \\
(-1.30)\end{array}$ & $\begin{array}{l}0.605 \\
(0.63)\end{array}$ \\
\hline F-value/AR(2) & $\begin{array}{l}95.78^{* * *} \\
{[0.000]}\end{array}$ & $\begin{array}{l}129.96^{* * * *} \\
{[0.000]}\end{array}$ & $\begin{array}{l}99.67^{* * * * *} \\
{[0.000]}\end{array}$ & $\begin{array}{l}107.18^{* * * *} \\
{[0.000]}\end{array}$ & $\begin{array}{l}185.16^{* * * *} \\
{[0.000]}\end{array}$ & $\begin{array}{l}97.20^{* * * * *} \\
{[0.000]}\end{array}$ & $\begin{array}{l}0.44 \\
{[0.660]}\end{array}$ & $\begin{array}{l}1.21 \\
{[0.225]}\end{array}$ & $\begin{array}{l}-1.19 \\
{[0.235]}\end{array}$ \\
\hline$R^{2} /$ Hansen test & 0.795 & 0.840 & 0.801 & 0.913 & 0.948 & 0.905 & $16.77 /[0.539]$ & $17.35 /[0.431]$ & $10.49 /[0.487]$ \\
\hline Year FE & Yes & Yes & Yes & Yes & Yes & Yes & Yes & Yes & Yes \\
\hline Province FE & Yes & Yes & Yes & Yes & Yes & Yes & No & No & No \\
\hline Observations & 210 & 210 & 210 & 210 & 210 & 210 & 180 & 180 & 180 \\
\hline
\end{tabular}

The values in brackets are $T$ values, and the values in [] are $P$ values

* represents $P<0.1$; ** represents $P<0.05$; *** represents $P<0.01$ 
(Table 5), the elastic coefficients of energy structure on carbon emissions are all around 0.35 , which are significant at the $1 \%$ significance level. Carbon emissions are positively correlated with the proportion of coal consumption. Every $1 \%$ increase in the proportion of coal consumption will lead to an increase of carbon emissions of about $0.35 \%$. This is closely related to China's coal-rich energy structure, which indicates that China is still in the stage of economic development dominated by traditional fossil energy. In contrast, clean energy consumption accounts for only a small proportion. Increasing coal consumption will aggravate carbon dioxide emissions. In this case, it is imperative to change the channel of energy use and gradually minimize the dependence of economic development on coal.

The number of permanent residents, per capita GDP, and energy intensity are significantly positively correlated with carbon emissions, and the previous level of carbon emissions is an important factor affecting the current level of carbon emissions (see Table 5). It means that the increase of population, economic development level, energy intensity, and carbon emission level in the early stage will lead to the increase of carbon emissions. With the increase of population and the expansion of urban scale, people's demand for food, clothing, housing, transportation, and other aspects of life increases correspondingly, and energy consumption increases accordingly (Ahmad et al. 2020). In addition, the increase of energy intensity indicates that economic growth depends on energy consumption, and the level of economic growth is not high. Moreover, the growth of social wealth means the improvement of people's living standards and the improvement of people's demand for quality life such as transportation, household appliances, and heating, which further induces the supply of high-carbon emission products. Finally, because it takes some time to break technical barriers, form environmental awareness, build policies and systems, and update fixed assets, it is difficult to change greatly in a short time. The current carbon emission level will be significantly affected by the previous period and eventually lead to the rise of energy consumption and carbon emission level.

\section{Regional heterogeneity}

\section{Heterogeneity of regional development level}

Taking into account the level of economic development and the industrial level in various parts of China, the division of the three major regions of the east, the middle, and the west basically reflects the regional characteristics and closely adheres to the strategic deployment of China's regional development (Yang et al. 2021a; Wu et al. 2021a). In order to verify whether the energy structure has different impacts on carbon emissions in different regions due to the existence of regional differences, the impact of energy structure on carbon emission in eastern, central, and western regions is regressed respectively. ${ }^{4}$

If $i \in$ eastern region, dummy $1=1$; if $i \in$ central region or western region, dummy $1=0$. If $i \in$ central region, dummy 2 $=1$; if $i \in$ eastern region or western region, dummy $2=0$. If $i \in$ western region, dummy $3=1$; if $i \in$ eastern region or central region, dummy $3=0$.

It can be seen from Table 6 that considering the total carbon emissions, the carbon intensity, and per capita carbon emissions, the impact of energy structure on carbon emissions is statistically significant. However, the influence coefficient of coal consumption ratio on carbon emissions in different regions is different. We can easily find that the central region > western region $>$ eastern region. Therefore, hypothesis 1 is proved.

\section{Heterogeneity of regional resource endowment}

In addition, because resource-based provinces have comparative advantages in resource factor input, they tend to attract resource-based industrial agglomeration and increase carbon emissions. Therefore, it is necessary to subdivide the overall sample into resource-based provinces and non-resource-based provinces to explore the heterogeneity of the impact of energy structure on carbon emissions. Specifically, this paper refers to the definition of resource-based areas by $\mathrm{Yu}$ et al. (2019) and comprehensively considers the output value of resourcebased industries and the proportion of employees. Nine typical resource-based provinces, namely Shanxi, Inner Mongolia, Heilongjiang, Guizhou, Yunnan, Shaanxi, Qinghai, Ningxia, and Xinjiang, are selected as the research objects ${ }^{5}$. If $i \in$ resource-based provinces, dummy $4=1$; if $i \in$ non-resource-based provinces, dummy $4=$ 0 . If $i \in$ non-resource-based provinces, dummy $5=1$; if $i \in$ resource-based provinces, dummy $5=0$.

The regression results in Table 7 show that for every $1 \%$ increase in the proportion of coal consumption, the total

\footnotetext{
${ }^{4}$ According to the division method of the National Bureau of statistics for the eastern, central, and western regions, the eastern region includes 11 provinces (cities) including Beijing, Tianjin, Hebei, Liaoning, Shanghai, Jiangsu, Zhejiang, Fujian, Shandong, Guangdong, and Hainan; the central region includes Shanxi, Jilin, Heilongjiang, Anhui, Jiangxi, Henan, and Hainan. The western region includes 11 provinces (cities) including Inner Mongolia, Guangxi, Chongqing, Sichuan, Guizhou, Yunnan, Shaanxi, Gansu, Qinghai, Ningxia, and Xinjiang.

${ }^{5}$ According to the data of the National Bureau of statistics, Shanxi, Inner Mongolia, Shaanxi, Guizhou, and Xinjiang are the top five provinces with coal reserves of more than 10 billion tons, accounting for about $74 \%$ of the total reserves in China. Heilongjiang, Shaanxi, and Xinjiang have oil reserves of more than 100 million tons, accounting for about $50 \%$ of the total oil reserves in China. Yunnan is known as China's "Kingdom of nonferrous metals" for its large mineral reserves and complete varieties.
} 
Table 6 Direct effect results based on heterogeneity of economic level

\begin{tabular}{|c|c|c|c|c|c|c|c|c|c|}
\hline \multirow[t]{2}{*}{ Explanatory variables } & \multicolumn{3}{|c|}{ Total carbon emissions } & \multicolumn{3}{|c|}{ The carbon intensity } & \multicolumn{3}{|c|}{ Per capita carbon emissions } \\
\hline & Eastern & Midland & Western & Eastern & Midland & Western & Eastern & Midland & Western \\
\hline \multirow[t]{2}{*}{$L . \ln C / L \cdot \ln C / L \cdot \ln C P$} & $0.217^{* * *}$ & $0.317^{* * *}$ & $0.160^{* *}$ & $0.725^{* * *}$ & $0.722^{* * *}$ & $0.220^{* * *}$ & $0.541^{* * * *}$ & $0.546^{* * *}$ & $0.173^{* * * *}$ \\
\hline & $(2.90)$ & $(6.31)$ & $(2.39)$ & $(3.94)$ & $(3.51)$ & $(7.40)$ & $(3.45)$ & $(9.69)$ & $(4.06)$ \\
\hline \multirow[t]{2}{*}{$\ln E \times d u m m y 1$} & $0.241^{* * * *}$ & & & $0.284^{* *}$ & & & $0.242^{*}$ & & \\
\hline & $(2.94)$ & & & $(2.02)$ & & & $(1.83)$ & & \\
\hline \multirow[t]{2}{*}{$\ln E \times d u m m y 2$} & & $0.443^{* *}$ & & & $0.735^{* *}$ & & & $0.721^{* * *}$ & \\
\hline & & $(2.56)$ & & & $(2.56)$ & & & $(2.49)$ & \\
\hline \multirow[t]{2}{*}{$\ln E \times d u m m y 3$} & & & $0.344^{* * * *}$ & & & $0.418^{* * * *}$ & & & $0.469^{* * * *}$ \\
\hline & & & $(3.65)$ & & & $(5.28)$ & & & $(3.72)$ \\
\hline \multirow[t]{2}{*}{$\ln P$} & $0.589^{* * * *}$ & $0.492^{* *}$ & $1.045^{* * *}$ & -0.013 & 0.118 & 0.113 & -0.431 & $0.292^{*}$ & 0.149 \\
\hline & $(7.31)$ & $(2.19)$ & $(8.34)$ & $(-0.15)$ & $(1.19)$ & $(1.01)$ & $(-1.48)$ & $(1.86)$ & $(1.01)$ \\
\hline \multirow[t]{2}{*}{$\ln A$} & $0.585^{* * * *}$ & 0.293 & $1.490^{* * * * *}$ & 0.320 & -0.335 & $0.456^{* * * *}$ & $0.994^{* * * *}$ & $1.603^{* * * *}$ & $1.786^{* * * *}$ \\
\hline & $(3.45)$ & $(1.30)$ & $(9.02)$ & $(1.41)$ & $(-1.18)$ & (3.10) & $(2.95)$ & $(5.92)$ & $(6.80)$ \\
\hline \multirow[t]{2}{*}{$\ln T$} & $0.492^{* * *}$ & $0.306^{* * * *}$ & $1.427^{* * * *}$ & $0.355^{*}$ & -0.164 & $0.930^{* * *}$ & $0.629^{* *}$ & $1.295^{* * *}$ & $1.181^{* * * *}$ \\
\hline & $(5.37)$ & $(2.67)$ & $(9.33)$ & (1.78) & $(-1.01)$ & (14.24) & $(2.54)$ & $(6.10)$ & (10.74) \\
\hline \multirow[t]{2}{*}{ lnrd } & $-0.515^{* * * *}$ & $-0.604^{* * * *}$ & -0.058 & -0.039 & $-0.932^{* * *}$ & $-0.425^{\text {**** }}$ & -0.053 & -0.215 & $-0.383^{* * *}$ \\
\hline & $(-3.44)$ & $(-3.36)$ & $(-0.42)$ & $(-0.26)$ & $(-2.79)$ & $(-7.55)$ & $(-0.37)$ & $(-1.27)$ & $(-3.07)$ \\
\hline \multirow[t]{2}{*}{$\ln r l z b$} & $0.150^{* * *}$ & 0.063 & -0.032 & $-0.157^{* * * *}$ & $-0.249^{* * *}$ & 0.041 & 0.029 & $-0.424^{* * *}$ & $-0.236^{* *}$ \\
\hline & $(3.17)$ & $(0.78)$ & $(-0.29)$ & $(-2.63)$ & $(-2.66)$ & $(0.83)$ & $(0.32)$ & $(-3.34)$ & $(-2.27)$ \\
\hline \multirow[t]{2}{*}{$\operatorname{lnfdi}$} & 0.057 & 0.018 & -0.083 & -0.025 & 0.065 & $-0.155^{* * * *}$ & 0.003 & -0.077 & -0.045 \\
\hline & $(0.79)$ & $(0.21)$ & $(-1.17)$ & $(-0.36)$ & $(0.67)$ & $(-3.61)$ & $(0.06)$ & $(-1.34)$ & $(-1.08)$ \\
\hline \multirow[t]{2}{*}{ lnmykf } & 0.024 & 0.049 & $0.166^{*}$ & $0.055^{*}$ & $0.063 *$ & $-0.038^{* * * *}$ & 0.013 & $0.304^{* * * *}$ & 0.036 \\
\hline & $(0.50)$ & (1.12) & $(1.76)$ & $(1.90)$ & (1.76) & $(-3.16)$ & $(0.28)$ & $(5.53)$ & $(0.79)$ \\
\hline \multirow[t]{2}{*}{ lnind } & 0.020 & 0.176 & $-1.253^{* * *}$ & $-0.496^{* *}$ & 0.234 & -0.205 & -0.135 & $-1.623^{* * *}$ & $-0.496^{* *}$ \\
\hline & $(0.09)$ & $(0.97)$ & $(-2.80)$ & $(-2.24)$ & $(0.70)$ & $(-1.30)$ & $(-0.70)$ & $(-4.20)$ & $(-2.13)$ \\
\hline \multirow[t]{2}{*}{$\operatorname{lncsh}$} & 0.391 & $1.421^{* *}$ & $-1.442^{* *}$ & -0.550 & $1.844^{* * * *}$ & 0.415 & $-1.217^{* *}$ & -1.255 & -0.900 \\
\hline & $(0.82)$ & $(2.02)$ & $(-2.29)$ & $(-0.50)$ & $(2.81)$ & (1.10) & $(-2.11)$ & $(-1.33)$ & $(-1.30)$ \\
\hline \multirow[t]{2}{*}{ dummyl } & $0.409^{*}$ & & & 0.310 & & & $0.885^{* *}$ & & \\
\hline & $(1.77)$ & & & $(1.10)$ & & & $(2.27)$ & & \\
\hline \multirow[t]{2}{*}{ dummy2 } & & 0.255 & & & -0.270 & & & $0.692^{* * * *}$ & \\
\hline & & $(0.88)$ & & & $(-0.83)$ & & & $(3.47)$ & \\
\hline \multirow[t]{2}{*}{ dummy3 } & & & -0.370 & & & $-0.367^{*}$ & & & -0.280 \\
\hline & & & $(-1.58)$ & & & $(-1.67)$ & & & $(-1.20)$ \\
\hline \multirow[t]{2}{*}{ Constant } & -1.278 & 0.071 & $-3.917^{* *}$ & -0.070 & -1.123 & $-3.781^{* * * *}$ & 1.273 & $-3.307^{* * *}$ & $-3.164^{* *}$ \\
\hline & $(-1.19)$ & $(0.03)$ & $(-2.53)$ & $(-0.09)$ & $(-1.12)$ & $(-5.34)$ & $(0.45)$ & $(-2.59)$ & $(-2.34)$ \\
\hline \multirow[t]{2}{*}{ F-value/AR(2) } & -0.94 & -0.83 & -0.32 & -0.12 & -0.52 & -0.86 & -0.70 & -1.25 & 0.53 \\
\hline & [0.349] & {$[0.406]$} & {$[0.752]$} & [0.907] & {$[0.605]$} & {$[0.390]$} & [0.485] & {$[0.210]$} & [0.598] \\
\hline \multirow[t]{2}{*}{ Hansen test } & 12.62 & 13.07 & 18.69 & 3.59 & 9.11 & 17.86 & 4.20 & 17.87 & 17.15 \\
\hline & {$[0.761]$} & {$[0.668]$} & {$[0.347]$} & [0.990] & {$[0.612]$} & {$[0.398]$} & [0.898] & {$[0.397]$} & {$[0.444]$} \\
\hline Year FE & Yes & Yes & Yes & Yes & Yes & Yes & Yes & Yes & Yes \\
\hline Province FE & No & No & No & No & No & No & No & No & No \\
\hline Observations & 180 & 180 & 180 & 180 & 180 & 180 & 180 & 180 & 180 \\
\hline
\end{tabular}

The values in brackets are $T$ values, and the values in [] are $P$ values

* represents $P<0.1$; ** represents $P<0.05$; *** represents $P<0.01$

carbon emissions of resource-based provinces will increase by $0.395 \%$ on average, while that of non-resource-based provinces will increase by $0.310 \%$ on average, which is significant at the $1 \%$ statistical level. It shows that 
Table 7 Direct effect results based on the heterogeneity of resource endowment

\begin{tabular}{|c|c|c|c|c|c|c|}
\hline \multirow[t]{2}{*}{ Explanatory variables } & \multicolumn{2}{|c|}{ Total carbon emissions } & \multicolumn{2}{|c|}{ The carbon intensity } & \multicolumn{2}{|c|}{ Per capita carbon emissions } \\
\hline & Resource & Non-resource & Resource & Non-resource & Resource & Non-resource \\
\hline \multirow[t]{2}{*}{$L . \ln C / L \cdot \ln C I / L . \ln C P$} & $0.221^{* *}$ & $0.129^{* * * *}$ & $0.570^{* * * *}$ & $0.493^{* * *}$ & $0.333^{* * * *}$ & $0.105^{* * * *}$ \\
\hline & $(2.45)$ & $(5.36)$ & $(7.29)$ & $(3.03)$ & $(6.08)$ & $(3.86)$ \\
\hline \multirow[t]{2}{*}{$\ln E \times d u m m y 4$} & $0.395^{* * *}$ & & $0.367^{* *}$ & & $0.348^{* * *}$ & \\
\hline & $(2.62)$ & & $(2.17)$ & & $(2.12)$ & \\
\hline \multirow[t]{2}{*}{$\ln E \times d u m m y 5$} & & $0.310^{\text {***** }}$ & & $0.246^{* * *}$ & & $0.286^{* * * *}$ \\
\hline & & (11.05) & & $(2.87)$ & & $(7.88)$ \\
\hline \multirow[t]{2}{*}{$\ln P$} & $0.689^{* * *}$ & $0.990^{* * * *}$ & $0.229^{*}$ & 0.124 & 0.170 & $0.159^{* * * *}$ \\
\hline & $(6.47)$ & $(28.93)$ & $(1.75)$ & $(0.94)$ & $(1.39)$ & $(2.70)$ \\
\hline \multirow[t]{2}{*}{$\ln A$} & 0.105 & $1.167^{* * *}$ & $0.361^{*}$ & 0.373 & 0.399 & $1.302^{* * * *}$ \\
\hline & $(0.31)$ & $(6.56)$ & $(1.96)$ & $(1.55)$ & $(0.93)$ & $(7.75)$ \\
\hline \multirow[t]{2}{*}{$\ln T$} & 0.058 & $1.093^{* * * *}$ & $0.995^{* * * *}$ & $0.572^{* *}$ & $0.874^{* *}$ & $1.376^{* * *}$ \\
\hline & $(0.34)$ & $(10.65)$ & $(6.54)$ & $(2.06)$ & $(2.42)$ & $(10.66)$ \\
\hline \multirow[t]{2}{*}{$\ln r d$} & $-0.696^{* * *}$ & -0.180 & $-0.393^{* * *}$ & -0.054 & -0.320 & -0.259 \\
\hline & $(-4.91)$ & $(-1.14)$ & $(-5.26)$ & $(-0.53)$ & $(-1.38)$ & $(-1.57)$ \\
\hline \multirow[t]{2}{*}{$\operatorname{lnrlz} b$} & $0.160^{*}$ & -0.101 & $0.169^{*}$ & $-0.159^{* *}$ & -0.251 & $-0.183^{* *}$ \\
\hline & $(1.96)$ & $(-1.54)$ & $(1.80)$ & $(-2.14)$ & $(-1.21)$ & $(-1.97)$ \\
\hline \multirow[t]{2}{*}{$\operatorname{lnfdi}$} & 0.146 & -0.019 & -0.091 & -0.015 & -0.060 & 0.007 \\
\hline & $(1.51)$ & $(-0.41)$ & $(-1.53)$ & $(-0.26)$ & $(-0.54)$ & $(0.11)$ \\
\hline \multirow[t]{2}{*}{ lnmykf } & -0.019 & $0.256^{* * * *}$ & $0.221^{* * * *}$ & -0.002 & 0.148 & $0.303^{* * *}$ \\
\hline & $(-0.54)$ & (7.09) & $(4.57)$ & $(-0.06)$ & $(1.22)$ & $(5.45)$ \\
\hline \multirow[t]{2}{*}{ lnind } & $0.450^{*}$ & $-0.969^{* * *}$ & $-1.039^{* * *}$ & $-0.349^{* *}$ & $-1.141^{* *}$ & $-1.205^{* * *}$ \\
\hline & (1.91) & $(-7.70)$ & $(-4.39)$ & $(-2.55)$ & $(-2.18)$ & $(-5.48)$ \\
\hline \multirow[t]{2}{*}{$\operatorname{lncsh}$} & 0.970 & -0.436 & -0.240 & -0.338 & 1.341 & -0.437 \\
\hline & $(1.02)$ & $(-0.99)$ & $(-0.42)$ & $(-0.49)$ & $(1.21)$ & $(-0.75)$ \\
\hline \multirow[t]{2}{*}{ dummy4 } & $0.309^{*}$ & & -0.349 & & 0.051 & \\
\hline & (1.73) & & $(-1.33)$ & & $(0.18)$ & \\
\hline \multirow[t]{2}{*}{ dummy5 } & & -0.062 & & 0.086 & & 0.058 \\
\hline & & $(-0.33)$ & & $(0.43)$ & & $(0.28)$ \\
\hline \multirow[t]{2}{*}{ Constant } & -1.588 & $-1.746^{*}$ & $-5.897^{* * * *}$ & -1.059 & -0.299 & $-2.067^{* *}$ \\
\hline & $(-1.06)$ & $(-1.81)$ & $(-4.12)$ & $(-0.72)$ & $(-0.15)$ & $(-2.36)$ \\
\hline \multirow[t]{2}{*}{$F$-value/AR(2) } & 0.95 & -1.57 & -1.06 & 0.14 & -0.85 & -1.09 \\
\hline & {$[0.342]$} & [0.115] & [0.291] & {$[0.886]$} & [0.394] & {$[0.278]$} \\
\hline \multirow[t]{2}{*}{ Hansen test } & 9.99 & 22.81 & 22.36 & 8.95 & 10.70 & 24.20 \\
\hline & {$[0.867]$} & {$[0.155]$} & {$[0.267]$} & {$[0.627]$} & {$[0.828]$} & [0.114] \\
\hline Year FE & Yes & Yes & Yes & Yes & Yes & Yes \\
\hline Province FE & No & No & No & No & No & No \\
\hline Observations & 180 & 180 & 180 & 180 & 180 & 180 \\
\hline
\end{tabular}

The values in brackets are $T$ values, and the values in [] are $P$ values

* represents $P<0.1$; ** represents $P<0.05$; *** represents $P<0.01$

the "contribution" of the energy structure to carbon emissions of resource-based provinces is greater than that of non-resource-based provinces. The regression results of the carbon intensity and per capita carbon emissions as explained variables also support this conclusion, thus verifying hypothesis 2 .

\section{Moderating effect of the digital economy on the relationship between energy structure and carbon emission}

Judging from the regression results at the national level (Table 8), the regression coefficients of the interaction terms 
between the energy structure and the digital economy are both significantly negative. It shows that the digital economy has a significant moderating effect on the impact of the energy structure on carbon emissions. The improvement of the development level of the digital economy will reduce the adverse impact of the energy structure on carbon emissions, thereby reducing carbon emissions. Therefore, hypothesis 3 is proved.

\section{Moderating effect (heterogeneity of regional development level)}

The regression results show that the interactive coefficients of energy structure and digital economy in the eastern region are more than $5 \%$, which is significantly negative, but the interactive coefficients of energy structure and digital economy in the central and western regions are not significant. It shows that the digital economy in the eastern region has a significant moderating effect on the impact of energy structure on carbon emissions, while there is no moderating effect of the digital economy in the central and western regions. The improvement of the development level of the digital economy can only reduce the negative impact of the eastern region's energy structure on carbon emissions, thereby reducing carbon emissions, and has no impact on the central and western regions (Table 9).

\section{Moderating effect (heterogeneity of regional resource endowment)}

Regional resources endowment heterogeneity results show that the interaction coefficients of the digital economy and energy structure of resource-based provinces are negative but not significant. However, the interaction coefficients of the digital economy and energy structure of non-resourcebased provinces are both negative and significant at the 5\% statistical level, which show that the regulation effect of the digital economy is not significant in resource-based provinces, but significant in non-resource-based provinces. Improving the level of the digital economy can reduce the negative impact of the energy structure of non-resource provinces on carbon emissions and reduce carbon emissions. Therefore, hypothesis 4 is proved in this paper (Table 10).

\section{Threshold effect}

\section{Test of threshold effect}

Tables 11,12, 13 show that the single threshold test shows the threshold value of the digital economy is significant at the statistical level of $1 \%$. The double threshold test shows that the threshold value of the digital economy is significant at the statistical level of 5\%. The triple threshold test failed to pass the significance level of $10 \%$. In summary, the energy structure has a significant dual-threshold feature of the digital economy when it affects carbon emissions. It is worth noting that whether or not control variables are added to the model, the panel threshold model rejects the zero hypothesis that there is no threshold effect, which indicates that the threshold effect of energy structure on carbon emissions exists. The impact of energy structure on carbon emissions depends on the regional digital economy. It is necessary to introduce the panel threshold model.

\section{Threshold effect regression structure}

When the digital economy is below the threshold of 3.7180 , the influence coefficient of energy structure on carbon emissions is 0.425 , which is significant at the statistical level of $1 \%$. When the digital economy crosses the threshold of 3.7180 , the impact coefficient of energy structure on carbon emissions decreases to 0.349 , which is significant at the statistical level of $1 \%$. When the digital economy crosses the threshold value of 4.7529 , the impact coefficient of energy structure on carbon emissions is only 0.255 , and it is significant at the level of $1 \%$. It shows that the impact of energy structure on carbon emissions has nonlinear characteristics. The higher the level of the digital economy, the smaller the adverse impact of energy structure on carbon emissions (Table 14).

Overall, the proportion of coal consumption has a positive impact on carbon emissions. Under the influence of different levels of the digital economy, the aggravating effect of energy structure on carbon emissions will be reduced to varying degrees. According to the estimated threshold variables, the whole sample is divided into high/medium/low digital economy regions. Due to space constraints, the results of each province in 2017 are shown in Table 15. It can be seen that the digital economy level ranking top 10 provinces are Beijing (5.0693), Fujian (5.0580), Guangdong (4.7529), Zhejiang (4.7060), Jiangsu (4.6791), Shandong(4.4431), Shanghai (4.4293), Sichuan (4.2014), Hebei (4.0411), and Liaoning (4.0187), and they mainly distribute in the eastern region and non-resource-based provinces.

The development levels of the digital economy in Beijing (5.0693), Fujian (5.0580), and Guangdong (4.7529) are higher than the threshold of 4.7529. Tianjin (3.3501), Qinghai (3.4590), Ningxia (3.4665), Jilin (3.4973), Gansu (3.5227), Heilongjiang (3.6198), Xinjiang (3.6794), Shanxi (3.7078), Guizhou (3.7180), and Jiangxi (3.7628) are the ten provinces with the lowest level of digital economic development, and they mainly distribute in the central and western regions and resource-based provinces. Interestingly, these results reflect that in the eastern region and non-resource-based provinces with higher economic development levels, the development level of the digital economy is higher than that in the central and western regions and resource-based provinces. 
Table 8 Regression results of moderating effect

\begin{tabular}{|c|c|c|c|c|c|c|c|c|c|}
\hline \multirow[t]{2}{*}{ Explanatory variables } & \multicolumn{6}{|c|}{ Static panel model (OLS) } & \multicolumn{3}{|c|}{ Dynamic panel model (SYS-GMM) } \\
\hline & $\mathrm{TC}$ & $\mathrm{CI}$ & $\mathrm{CP}$ & $\mathrm{TC}$ & $\mathrm{CI}$ & $\mathrm{CP}$ & $\mathrm{TC}$ & $\mathrm{CI}$ & $\mathrm{CP}$ \\
\hline \multirow[t]{2}{*}{$\ln E$} & $0.393^{* * *}$ & $0.417^{* * * *}$ & $0.392^{* * *}$ & $0.379^{* * *}$ & $0.379^{* * * *}$ & $0.379^{* * *}$ & $0.394^{* * * *}$ & $0.270^{* * * *}$ & $0.326^{* * * *}$ \\
\hline & $(24.05)$ & $(21.96)$ & $(25.38)$ & $(37.61)$ & $(37.61)$ & $(37.61)$ & $(3.83)$ & $(4.31)$ & $(4.21)$ \\
\hline \multirow[t]{2}{*}{$\ln D$} & 0.018 & $-0.137^{* * *}$ & 0.014 & -0.039 & -0.039 & -0.039 & 0.048 & $0.182^{* * *}$ & 0.066 \\
\hline & $(0.46)$ & $(3.09)$ & $(0.39)$ & $(1.61)$ & $(1.61)$ & $(1.61)$ & $(0.98)$ & $(4.46)$ & $(1.39)$ \\
\hline \multirow[t]{2}{*}{$\ln E \times \ln D$} & $-0.086^{* * * *}$ & $-0.073^{* * * *}$ & $-0.078^{* * * *}$ & $-0.112^{* * * *}$ & $-0.112^{* * *}$ & $-0.112^{* * * *}$ & $-0.121^{* *}$ & $-0.112^{* * * *}$ & $-0.149^{* * * *}$ \\
\hline & $(-5.03)$ & $(-3.66)$ & $(-4.84)$ & $(-8.98)$ & $(-8.98)$ & $(-8.98)$ & $(-2.57)$ & $(-3.94)$ & $(-3.45)$ \\
\hline \multirow[t]{2}{*}{$\ln P$} & & & & $0.953^{* * * *}$ & -0.047 & -0.047 & 0.438 & -0.003 & -0.064 \\
\hline & & & & $(3.94)$ & $(-0.19)$ & $(-0.19)$ & $(1.63)$ & $(-0.04)$ & $(-1.42)$ \\
\hline \multirow[t]{2}{*}{$\ln A$} & & & & $0.855^{* * * *}$ & $-0.145^{*}$ & $0.855^{* * * * *}$ & $0.806^{* * *}$ & $-0.376^{*}$ & $0.780^{* * *}$ \\
\hline & & & & $(10.73)$ & $(-1.82)$ & $(10.73)$ & $(2.12)$ & $(-1.86)$ & $(2.46)$ \\
\hline \multirow[t]{2}{*}{$\ln T$} & & & & $0.847^{* * *}$ & $0.847^{* * *}$ & $0.847^{* * * *}$ & $0.800^{* * *}$ & $0.383^{* * *}$ & $0.586^{* * *}$ \\
\hline & & & & $(14.85)$ & $(14.85)$ & $(14.85)$ & $(3.03)$ & (2.97) & $(3.53)$ \\
\hline \multirow[t]{2}{*}{ lnrd } & & & & 0.016 & 0.016 & 0.016 & $0.373^{* *}$ & -0.052 & -0.059 \\
\hline & & & & $(0.41)$ & $(0.41)$ & $(0.41)$ & $(2.12)$ & $(-0.33)$ & $(-1.16)$ \\
\hline \multirow[t]{2}{*}{$\ln r l z b$} & & & & $-0.080^{* * *}$ & $-0.080^{* *}$ & $-0.080^{* *}$ & -0.049 & -0.031 & -0.005 \\
\hline & & & & $(-2.56)$ & $(-2.56)$ & $(-2.56)$ & $(-0.96)$ & $(-0.60)$ & $(-0.09)$ \\
\hline \multirow[t]{2}{*}{$\ln f d i$} & & & & -0.023 & -0.023 & -0.023 & $-0.094^{*}$ & $-0.089^{* *}$ & 0.010 \\
\hline & & & & $(-1.50)$ & $(-1.50)$ & $(-1.50)$ & $(-1.87)$ & $(-2.05)$ & $(0.32)$ \\
\hline \multirow[t]{2}{*}{ lnmykf } & & & & $0.027^{* *}$ & $0.027^{* *}$ & $0.027^{* *}$ & 0.078 & 0.032 & $0.064^{*}$ \\
\hline & & & & $(2.27)$ & $(2.27)$ & $(2.27)$ & $(1.34)$ & $(1.35)$ & $(1.71)$ \\
\hline \multirow[t]{2}{*}{ lnind } & & & & 0.036 & 0.036 & 0.036 & -0.356 & 0.006 & 0.028 \\
\hline & & & & $(0.50)$ & $(0.50)$ & $(0.50)$ & $(-1.36)$ & $(0.04)$ & $(0.17)$ \\
\hline \multirow[t]{2}{*}{$\operatorname{lncsh}$} & & & & 0.223 & 0.223 & 0.223 & -0.454 & $0.982^{* * *}$ & -0.429 \\
\hline & & & & $(1.42)$ & $(1.42)$ & $(1.42)$ & $(-0.52)$ & $(2.06)$ & $(-0.83)$ \\
\hline \multirow[t]{2}{*}{$L . \ln C$} & & & & & & & $0.517^{* * *}$ & & \\
\hline & & & & & & & $(2.78)$ & & \\
\hline \multirow[t]{2}{*}{ L. $\ln C I$} & & & & & & & & $0.593^{* * * *}$ & \\
\hline & & & & & & & & $(5.23)$ & \\
\hline \multirow[t]{2}{*}{ L. $\ln C P$} & & & & & & & & & $0.430^{* * * *}$ \\
\hline & & & & & & & & & $(2.92)$ \\
\hline \multirow[t]{2}{*}{ Constant } & $9.487^{* * *}$ & $0.503^{* * *}$ & $1.321^{* * *}$ & 1.697 & 1.697 & 1.697 & 1.437 & 0.570 & -0.170 \\
\hline & (80.78) & $(3.68)$ & (11.88) & $(0.85)$ & $(0.85)$ & $(0.85)$ & $(0.70)$ & $(0.41)$ & $(-0.29)$ \\
\hline \multirow[t]{2}{*}{ F-value/AR(2) } & 88.57 & 113.25 & 90.79 & 145.51 & 248.11 & 132.37 & -1.32 & -0.65 & -0.51 \\
\hline & {$[0.000]$} & {$[0.000]$} & {$[0.000]$} & {$[0.000]$} & {$[0.000]$} & {$[0.000]$} & {$[0.186]$} & {$[0.516]$} & {$[0.607]$} \\
\hline$R^{2} /$ Hansen test & 0.823 & 0.856 & 0.827 & 0.942 & 0.965 & 0.936 & $7.84 /[0.449]$ & $9.98 /[0.442]$ & $14.03 /[0.172]$ \\
\hline Year FE & Yes & Yes & Yes & Yes & Yes & Yes & Yes & Yes & Yes \\
\hline Province FE & Yes & Yes & Yes & Yes & Yes & Yes & No & No & No \\
\hline Observations & 210 & 210 & 210 & 210 & 210 & 210 & 180 & 180 & 180 \\
\hline
\end{tabular}

The values in brackets are $T$ values, and the values in [] are $P$ values

* represents $P<0.1$; ** represents $P<0.05$; *** represents $P<0.01$ 
Table 9 Regression results of regulatory effect based on heterogeneity of local economic level

\begin{tabular}{|c|c|c|c|c|c|c|c|c|c|}
\hline \multirow[t]{2}{*}{ Explanatory variables } & \multicolumn{3}{|c|}{ Total carbon emissions } & \multicolumn{3}{|c|}{ The carbon intensity } & \multicolumn{3}{|c|}{ Per capita carbon emissions } \\
\hline & Eastern & Midland & Western & Eastern & Midland & Western & Eastern & Midland & Western \\
\hline \multirow[t]{2}{*}{$\ln E$} & $0.280^{* * * *}$ & $0.424^{* * * *}$ & $0.187^{* *}$ & $0.372^{* * * *}$ & $0.443^{* * *}$ & $0.483^{* * * *}$ & $0.202^{* * * *}$ & $0.168^{* * * *}$ & $0.331^{* * * *}$ \\
\hline & $(2.91)$ & (11.13) & $(2.37)$ & $(5.40)$ & $(5.06)$ & $(4.89)$ & $(3.24)$ & $(2.81)$ & $(3.67)$ \\
\hline \multirow[t]{2}{*}{$\ln D$} & 0.060 & -0.033 & 0.061 & $0.146^{* * * *}$ & 0.165 & $0.145^{* *}$ & 0.060 & -0.097 & 0.036 \\
\hline & $(0.96)$ & $(-0.74)$ & $(1.21)$ & $(3.51)$ & $(1.11)$ & $(2.40)$ & $(1.57)$ & $(-1.15)$ & $(0.68)$ \\
\hline \multirow[t]{2}{*}{$\ln E \times \ln D \times d u m m y 1$} & $-0.166^{* *}$ & & & $-0.122^{* * *}$ & & & $-0.109^{* *}$ & & \\
\hline & $(-2.18)$ & & & $(-2.90)$ & & & $(-2.09)$ & & \\
\hline \multirow[t]{2}{*}{$\ln E \times \ln D \times d u m m y 2$} & & 0.509 & & & -0.102 & & & 0.632 & \\
\hline & & $(1.59)$ & & & $(-0.09)$ & & & $(1.47)$ & \\
\hline \multirow[t]{2}{*}{$\ln E \times \ln D \times d u m m y 3$} & & & -0.159 & & & -0.082 & & & -0.187 \\
\hline & & & $(-1.30)$ & & & $(-0.65)$ & & & $(-1.01)$ \\
\hline \multirow[t]{2}{*}{$\ln P$} & $0.512^{* * * *}$ & $1.032^{* * * *}$ & 0.212 & 0.006 & 0.228 & 0.270 & $-0.068^{*}$ & 0.007 & 0.190 \\
\hline & $(2.65)$ & $(9.97)$ & $(1.23)$ & $(0.06)$ & $(1.25)$ & (1.03) & $(-1.86)$ & $(0.08)$ & $(0.36)$ \\
\hline \multirow[t]{2}{*}{$\ln A$} & $0.855^{* * *}$ & $1.127^{* * *}$ & 0.244 & 0.016 & 0.264 & 0.362 & $0.381^{* *}$ & $0.804^{* * *}$ & $1.036^{*}$ \\
\hline & $(3.30)$ & $(5.13)$ & $(0.97)$ & $(0.09)$ & $(0.70)$ & $(0.81)$ & $(2.13)$ & (3.14) & $(1.84)$ \\
\hline \multirow[t]{2}{*}{$\ln T$} & $0.660^{* * * *}$ & $0.931^{* * * *}$ & $0.212^{*}$ & $0.735^{* * * *}$ & $0.585^{* * *}$ & $0.647^{* *}$ & $0.394^{* * * *}$ & $0.366^{* * * *}$ & $0.753^{*}$ \\
\hline & $(3.07)$ & $(5.89)$ & (1.68) & $(4.51)$ & $(2.36)$ & (1.98) & $(2.77)$ & $(2.92)$ & (1.93) \\
\hline \multirow[t]{2}{*}{ lnrd } & 0.117 & -0.210 & 0.041 & -0.025 & 0.490 & 0.565 & -0.053 & -0.093 & -0.004 \\
\hline & $(1.25)$ & $(-1.12)$ & $(0.57)$ & $(-0.26)$ & $(1.29)$ & $(1.53)$ & $(-1.58)$ & $(-0.51)$ & $(-0.01)$ \\
\hline \multirow[t]{2}{*}{$\operatorname{lnrlz} b$} & 0.015 & $-0.150^{* * * *}$ & -0.080 & 0.037 & 0.012 & 0.078 & 0.027 & $-0.122^{*}$ & 0.113 \\
\hline & $(0.31)$ & $(-3.37)$ & $(-1.46)$ & $(0.89)$ & $(0.10)$ & $(0.67)$ & $(0.46)$ & $(-1.71)$ & (1.04) \\
\hline \multirow[t]{2}{*}{$\ln f d i$} & $-0.100^{* *}$ & -0.047 & 0.030 & $-0.124^{* * *}$ & $-0.264^{* * *}$ & $-0.342^{\text {*** }}$ & -0.039 & 0.024 & -0.025 \\
\hline & $(-2.42)$ & $(-1.21)$ & (1.15) & $(-3.02)$ & $(-2.01)$ & $(-2.10)$ & $(-1.44)$ & $(0.83)$ & $(-0.48)$ \\
\hline \multirow[t]{2}{*}{ lnmykf } & -0.073 & $0.083^{* * * *}$ & 0.008 & 0.009 & 0.011 & 0.046 & 0.047 & -0.008 & -0.035 \\
\hline & $(-1.14)$ & $(2.73)$ & $(0.18)$ & $(0.34)$ & $(0.32)$ & $(1.21)$ & (1.17) & $(-0.24)$ & $(-0.51)$ \\
\hline \multirow[t]{2}{*}{ Inind } & -0.001 & $-0.459^{*}$ & 0.017 & -0.119 & -0.429 & -0.590 & 0.014 & -0.165 & -0.079 \\
\hline & $(-0.01)$ & $(-1.84)$ & $(0.12)$ & $(-0.69)$ & $(-0.91)$ & $(-1.23)$ & $(0.10)$ & $(-0.80)$ & $(-0.23)$ \\
\hline \multirow[t]{2}{*}{$\operatorname{lncsh}$} & $-0.998^{*}$ & 0.437 & -0.063 & -0.134 & -0.592 & -0.360 & -0.110 & -0.498 & -1.259 \\
\hline & $(-1.93)$ & $(0.57)$ & $(-0.12)$ & $(-0.21)$ & $(-0.67)$ & $(-0.26)$ & $(-0.47)$ & $(-1.01)$ & $(-1.07)$ \\
\hline \multirow[t]{2}{*}{ dummyl } & $0.413^{*}$ & & & 0.314 & & & 0.099 & & \\
\hline & $(1.80)$ & & & (1.63) & & & $(1.35)$ & & \\
\hline \multirow[t]{2}{*}{ dummy2 } & & -0.100 & & & -0.326 & & & -0.147 & \\
\hline & & $(-0.93)$ & & & $(-1.02)$ & & & $(-0.87)$ & \\
\hline \multirow[t]{2}{*}{ dummy3 } & & & 0.054 & & & 0.171 & & & -0.173 \\
\hline & & & $(0.51)$ & & & $(0.42)$ & & & $(-0.59)$ \\
\hline$L \cdot \ln C / L \cdot \ln C I / L \cdot \ln C P$ & $0.477^{* * * *}$ & $0.037^{* * * *}$ & $0.679^{* * * *}$ & $0.309^{* *}$ & $0.639^{* * * *}$ & $0.648^{* *}$ & $0.579^{* * * *}$ & $0.550^{* * * *}$ & $0.335^{* *}$ \\
\hline & $(3.49)$ & $(2.70)$ & $(4.68)$ & $(2.20)$ & $(4.38)$ & $(2.43)$ & $(4.58)$ & $(4.30)$ & $(2.53)$ \\
\hline Constant & -1.072 & -0.226 & $1.674^{*}$ & -1.255 & -1.572 & -2.331 & 0.012 & 0.010 & -3.752 \\
\hline & $(-0.64)$ & $(-0.29)$ & $(1.72)$ & $(-1.00)$ & $(-0.66)$ & $(-0.79)$ & $(0.02)$ & $(0.01)$ & $(-0.59)$ \\
\hline$F$-value/AR(2) & -1.14 & 0.97 & -0.48 & -0.57 & 0.08 & 0.18 & -0.97 & -0.11 & -0.10 \\
\hline & {$[0.253]$} & {$[0.333]$} & {$[0.628]$} & {$[0.571]$} & {$[0.937]$} & {$[0.860]$} & {$[0.330]$} & {$[0.909]$} & {$[0.920]$} \\
\hline Hansen test & 4.15 & 11.91 & 13.67 & 3.75 & 2.63 & 1.94 & 13.73 & 11.45 & 10.65 \\
\hline & {$[0.843]$} & {$[0.613]$} & {$[0.134]$} & {$[0.927]$} & {$[0.955]$} & {$[0.983]$} & {$[0.318]$} & {$[0.246]$} & {$[0.155]$} \\
\hline Year FE & Yes & Yes & Yes & Yes & Yes & Yes & Yes & Yes & Yes \\
\hline Province FE & No & No & No & No & No & No & No & No & No \\
\hline Observations & 180 & 180 & 180 & 180 & 180 & 180 & 180 & 180 & 180 \\
\hline
\end{tabular}

The values in brackets are $T$ values, and the values in [] are $P$ values

* represents $P<0.1$; ** represents $P<0.05$; *** represents $P<0.01$ 
Table 10 Regression results of regulatory effect based on heterogeneity of resource endowment

\begin{tabular}{|c|c|c|c|c|c|c|}
\hline \multirow[t]{2}{*}{ Explanatory variables } & \multirow{2}{*}{$\begin{array}{l}\text { Total carbon emissions } \\
\text { Resource }\end{array}$} & \multicolumn{3}{|c|}{ The carbon intensity } & \multicolumn{2}{|c|}{ Per capita carbon emissions } \\
\hline & & Non-resource & Resource & Non-resource & Resource & Non-resource \\
\hline \multirow[t]{2}{*}{$\ln E$} & $0.451^{* * * * *}$ & $0.389^{* * * *}$ & $0.422^{* * * *}$ & $0.345^{* * * *}$ & $0.260^{* * * *}$ & $0.283^{* * * *}$ \\
\hline & $(12.22)$ & $(3.86)$ & $(12.35)$ & $(6.18)$ & $(4.68)$ & $(3.71)$ \\
\hline \multirow[t]{2}{*}{$\ln D$} & $0.058^{*}$ & 0.041 & $0.103^{* * * *}$ & $0.144 * *$ & $0.094^{* * * *}$ & 0.058 \\
\hline & $(1.86)$ & $(0.96)$ & $(4.18)$ & $(2.37)$ & $(2.96)$ & $(1.57)$ \\
\hline \multirow[t]{2}{*}{$\ln E \times \ln D \times$ dummy 4} & -0.457 & & -0.123 & & -0.314 & \\
\hline & $(-1.31)$ & & $(-0.54)$ & & $(-1.14)$ & \\
\hline \multirow[t]{2}{*}{$\ln E \times \ln D \times$ dummy 5} & & $-0.146^{* * *}$ & & $-0.106^{* * * *}$ & & $-0.104^{* *}$ \\
\hline & & $(-3.13)$ & & & & $(-2.34)$ \\
\hline \multirow[t]{2}{*}{$\ln P$} & $0.867^{* * * *}$ & $0.593^{* *}$ & -0.096 & -0.080 & -0.077 & -0.094 \\
\hline & $(9.74)$ & $(2.46)$ & $(-1.15)$ & $(-1.60)$ & $(-1.21)$ & $(-1.41)$ \\
\hline \multirow[t]{2}{*}{$\ln A$} & $1.446^{* * * *}$ & $1.094^{* * * *}$ & $0.338^{*}$ & 0.141 & $0.755^{* * *}$ & $0.877^{* * * *}$ \\
\hline & $(6.43)$ & $(3.62)$ & $(1.81)$ & $(0.63)$ & $(2.36)$ & (3.53) \\
\hline \multirow[t]{2}{*}{$\ln T$} & $0.941^{\text {**** }}$ & $0.872^{* * * *}$ & $0.970^{* * * *}$ & $0.643^{\text {***** }}$ & $0.535^{* * *}$ & $0.604^{* * * *}$ \\
\hline & (10.13) & (3.39) & $(9.84)$ & $(3.22)$ & $(3.75)$ & $(3.36)$ \\
\hline \multirow[t]{2}{*}{$\ln r d$} & -0.057 & 0.272 & -0.065 & -0.012 & 0.046 & 0.137 \\
\hline & $(-0.26)$ & (1.64) & $(-0.38)$ & $(-0.08)$ & $(0.43)$ & $(0.93)$ \\
\hline \multirow[t]{2}{*}{ lnrlzb } & $-0.129^{* *}$ & -0.031 & 0.046 & 0.012 & -0.053 & -0.085 \\
\hline & $(-2.06)$ & $(-0.53)$ & $(0.99)$ & $(0.22)$ & $(-0.91)$ & $(-1.21)$ \\
\hline \multirow[t]{2}{*}{$\operatorname{lnfdi}$} & 0.011 & $-0.071^{*}$ & $-0.078^{* *}$ & $-0.129^{* *}$ & 0.029 & -0.009 \\
\hline & $(0.29)$ & $(-1.84)$ & $(-2.14)$ & $(-2.36)$ & $(1.26)$ & $(-0.33)$ \\
\hline \multirow[t]{2}{*}{ lnmykf } & $0.119^{* * * *}$ & 0.027 & -0.001 & 0.012 & 0.029 & 0.027 \\
\hline & $(3.04)$ & $(0.53)$ & $(-0.09)$ & $(0.61)$ & $(0.88)$ & $(0.67)$ \\
\hline \multirow[t]{2}{*}{ lnind } & $-0.281^{*}$ & -0.258 & -0.256 & -0.042 & -0.209 & -0.157 \\
\hline & $(-1.66)$ & $(-1.21)$ & $(-1.57)$ & $(-0.22)$ & $(-1.54)$ & $(-1.01)$ \\
\hline \multirow[t]{2}{*}{$\operatorname{lncsh}$} & -0.670 & $-1.155^{\text {*** }}$ & -0.960 & 0.196 & -0.709 & $-1.018^{*}$ \\
\hline & $(-0.94)$ & $(-2.11)$ & $(-1.45)$ & $(0.37)$ & $(-0.91)$ & $(-1.93)$ \\
\hline \multirow[t]{2}{*}{ duтmy4 } & 0.081 & & -0.159 & & 0.017 & \\
\hline & $(0.72)$ & & $(-1.05)$ & & $(0.19)$ & \\
\hline \multirow[t]{2}{*}{ dummy 5} & & 0.062 & & 0.153 & & 0.094 \\
\hline & & $(0.51)$ & & (1.05) & & $(1.23)$ \\
\hline \multirow[t]{2}{*}{$L \cdot \ln C / L \cdot \ln C I / L \cdot \ln C P$} & $0.040^{* * *}$ & $0.477^{* * * *}$ & $0.072^{* * *}$ & $0.498^{* * * *}$ & $0.420^{* * * *}$ & $0.518^{\text {***** }}$ \\
\hline & $(2.63)$ & $(2.80)$ & (3.13) & $(4.35)$ & $(3.62)$ & $(3.60)$ \\
\hline \multirow[t]{2}{*}{ Constant } & 0.362 & -0.869 & $-1.362^{*}$ & -0.222 & 0.271 & 0.636 \\
\hline & $(0.29)$ & $(-0.49)$ & $(-1.88)$ & $(-0.22)$ & $(0.33)$ & $(0.55)$ \\
\hline \multirow[t]{2}{*}{ F-value/AR(2) } & 0.05 & -0.10 & 1.50 & -0.30 & -0.76 & -0.27 \\
\hline & {$[0.962]$} & {$[0.917]$} & {$[0.134]$} & {$[0.765]$} & {$[0.445]$} & {$[0.787]$} \\
\hline \multirow[t]{2}{*}{ Hansen test } & 19.39 & 8.40 & 14.13 & 7.07 & 10.96 & 11.47 \\
\hline & {$[0.111]$} & {$[0.396]$} & {$[0.365]$} & {$[0.630]$} & {$[0.278]$} & {$[0.245]$} \\
\hline Year FE & Yes & Yes & Yes & Yes & Yes & Yes \\
\hline Province FE & No & No & No & No & No & No \\
\hline Observations & 180 & 180 & 180 & 180 & 180 & 180 \\
\hline
\end{tabular}

The values in brackets are $T$ values, and the values in [] are $P$ values

* represents $P<0.1$; ** represents $P<0.05$; *** represents $P<0.01$

\section{Discussion}

\section{Discussion of direct effect estimation results}

According to the direct effect regression results, the following discussion can be drawn:

As can be seen from the results in Table 5, with the increase of the proportion of coal consumption, carbon emissions will also increase. It shows that China's carbon emission level is still highly related to the energy consumption structure. From Figure 1, both the proportion of coal consumption and carbon emissions presented an increasing trend from 2004 to 2017. It can be seen from Table 1 that the average growth rates of carbon emissions are all positive, and Hainan, Xinjiang, Guangxi, Ningxia, and Inner Mongolia are the five provinces with the fastest growth rate of carbon emissions, and their carbon emission growth rates are all over $10 \%$. And the growth rate of carbon emissions in Inner Mongolia is faster than economic growth, and the quality of energy consumption is obviously low (Rehman et al. 2021a, 2021b). One possible reason is that these provinces have a relatively low level of economic development. In the early stage of economic development, energy consumption is relatively large, 
Table 11 Total carbon emissions as explained variable

\begin{tabular}{llllllll}
\hline $\begin{array}{l}\text { The number of } \\
\text { thresholds } \\
\text { (total carbon emissions) }\end{array}$ & $\begin{array}{l}\text { The threshold } \\
\text { value }\end{array}$ & The $F$ value & $\begin{array}{l}P \\
\text { values }\end{array}$ & & & \multicolumn{3}{l}{ The critical value } \\
\cline { 5 - 8 } \cline { 4 - 7 } & & & & $1 \%$ & $5 \%$ & $10 \%$ \\
\hline Single threshold test & 4.7529 & 77.53 & 0.000 & 36.8878 & 27.2855 & 22.0899 \\
Double threshold test & 3.7180 & 52.97 & 0.014 & 60.1436 & 25.5798 & 19.3863 \\
Triple threshold test & 2.7551 & 21.42 & 0.7080 & 110.990 & 68.7736 & 54.0355 \\
\hline
\end{tabular}

which brings relatively high economic growth $(\mathrm{Wu}$ et al. 2018; Wu et al. 2021b).

The intensity of energy structure's impact on carbon emissions varies significantly with different levels of economic development. The results in Table 6 show that the eastern energy structure has the least impact on carbon emissions, while the western is in the middle and the central is the largest. The reason is that the central region is not only the main agricultural production area, but also the traditional production area of coal and other energy, and the secondary and tertiary industries started late (Jin and Wu 2013; Song and Peng 2019). With the advancement of China's industrial structure, the energy and resource-based industries in the eastern region have to find the best transfer place under the constraints of the livable environment of local residents and the rising cost (Yang et al. 2021b; Hao et al. 2021b). The central region has the advantages of resources, transportation, and population, which will reduce the production cost and transfer cost of enterprises. Therefore, it has become an ideal place to undertake the eliminated industries in the eastern region (Mao 2019). In addition, the low added value of these backward industries is not conducive to the improvement of technical efficiency and the reduction of carbon emissions. The economic development of the western region is relatively backward, but it contains abundant wind energy, natural gas, and solar energy resources. Under the western development strategy, the implementation of the West-East natural gas transmission project and the West-East power transmission project has slowed down the dependence on coal and other traditional energy to a certain extent (Tian et al. 2006). At the same time, natural gas and hydropower replace coal as primary energy, which also contributes to reducing $\mathrm{CO}_{2}$ and other greenhouse gas emissions. Combined with Table 6 and China's carbon emission calculation results (Table 1), the eastern region accounts for 6 of the 10 provinces with the largest carbon emission, but the energy structure of the eastern region has the least impact on carbon emissions; from the results of average growth rates of carbon emissions, the growth rate of carbon emissions in eastern China is low. It can be seen that the energy demand of the eastern region is transferred across regions (Wu et al. 2020). China's energy geographic spatial reallocation not only transforms the resource advantages of the western region into economic advantages, but also makes an indelible contribution to the economy and environment of the eastern region; carbon emissions in the western region have also increased (Guo and Ge 2004).

The impact of energy structure on carbon emissions is heterogeneous due to the difference of resource endowment. The contribution of energy structure to carbon emissions in resource-based provinces is greater than that of nonresource-based provinces. One possible explanation is that, for resource-based provinces, it is undoubtedly a "shortcut" to drive economic growth by taking advantage of local resource industries to drive economic growth, but this growth model naturally attracts resource-intensive industrial agglomeration (Wang et al. 2019). The excessive dependence of resource-based provinces on resources will lead to the simplification of the local industrial structure, and regional development is likely to form the "inertia" (Fouquet 2016). Moreover, the industries pursuing resources are mostly high energy consumption and high emission sectors (Hao and Deng 2019). There is no doubt that the high level of energy consumption leads to an increase in carbon emissions.

\section{Discussion on the estimation results of the moderating effect}

First of all, at the national level, the digital economy has an obvious moderating effect on the relationship between energy structure and carbon emissions. According to Eq. 5, the
Table 12 Carbon emission intensity is taken as the explained variable

\begin{tabular}{|c|c|c|c|c|c|c|}
\hline \multirow{2}{*}{$\begin{array}{l}\text { The number of } \\
\text { thresholds } \\
\text { (The carbon intensity) }\end{array}$} & \multirow{2}{*}{$\begin{array}{l}\text { The threshold } \\
\text { value }\end{array}$} & \multirow[t]{2}{*}{ The $F$ value } & \multirow{2}{*}{$\begin{array}{l}P \\
\text { values }\end{array}$} & \multicolumn{3}{|c|}{ The critical value } \\
\hline & & & & $1 \%$ & $5 \%$ & $10 \%$ \\
\hline Single threshold test & 4.7529 & 77.53 & 0.000 & 37.0517 & 25.5707 & 22.5935 \\
\hline Double threshold test & 3.7180 & 52.97 & 0.018 & 76.3572 & 26.8427 & 18.4189 \\
\hline Triple threshold test & 2.7551 & 21.42 & 0.664 & 96.7156 & 59.1368 & 49.4026 \\
\hline
\end{tabular}


Table 13 Per capita carbon emissions as explained variable

\begin{tabular}{|c|c|c|c|c|c|c|}
\hline \multirow{2}{*}{$\begin{array}{l}\text { The number of thresholds } \\
\text { (Per capita carbon } \\
\text { emissions) }\end{array}$} & \multirow{2}{*}{$\begin{array}{l}\text { The threshold } \\
\text { value }\end{array}$} & \multirow{2}{*}{$\begin{array}{l}\text { The } F \\
\text { value }\end{array}$} & \multirow{2}{*}{$\begin{array}{l}P \\
\text { values }\end{array}$} & \multicolumn{3}{|c|}{ The critical value } \\
\hline & & & & $1 \%$ & $5 \%$ & $10 \%$ \\
\hline Single threshold test & 4.7529 & 77.53 & 0.000 & 37.9399 & 26.3816 & 22.4251 \\
\hline Double threshold test & 3.7180 & 52.97 & 0.010 & 51.3781 & 22.0493 & 17.2228 \\
\hline Triple threshold test & 2.7551 & 21.42 & 0.6980 & 103.209 & 61.8878 & 49.9699 \\
\hline
\end{tabular}

marginal contribution of the energy structure to carbon emissions is a function of the digital economy. Since the influence coefficients of the interaction terms of the digital economy on carbon emissions are all significantly negative (Table 8), the higher the development level of digital economy, the greater the contribution of the moderating effect of digital economy to carbon emission reduction.
The moderating role of the digital economy in the relationship between energy structure and carbon emissions is significant in the eastern region, but not significant in the central and western regions. This may be because the eastern region has a higher level of economic development than the central and western regions and a better environment for the development of the digital economy, which is conducive to the regulation of
Table 14 Regression results of the threshold effect

\begin{tabular}{|c|c|c|c|}
\hline Threshold effect parameter estimation results & $\begin{array}{l}\text { (1) } \\
\mathrm{TC}\end{array}$ & $\begin{array}{l}(2) \\
\text { CI }\end{array}$ & $\begin{array}{l}\text { (3) } \\
\mathrm{CP}\end{array}$ \\
\hline $\ln P$ & $\begin{array}{l}1.402^{* *} \\
(6.42)\end{array}$ & $\begin{array}{l}0.402^{*} \\
(1.84)\end{array}$ & $\begin{array}{l}0.402^{*} \\
(1.84)\end{array}$ \\
\hline $\ln A$ & $\begin{array}{l}0.942^{* *} \\
(15.06)\end{array}$ & $\begin{array}{l}-0.058 \\
(-0.92)\end{array}$ & $\begin{array}{l}0.942^{* *} \\
(15.06)\end{array}$ \\
\hline $\ln T$ & $\begin{array}{l}0.784^{* *} \\
(15.27)\end{array}$ & $\begin{array}{l}0.784^{* *} \\
(15.27)\end{array}$ & $\begin{array}{l}0.784^{* *} \\
(15.27)\end{array}$ \\
\hline lnrd & $\begin{array}{l}0.012 \\
(0.37)\end{array}$ & $\begin{array}{l}0.012 \\
(0.37)\end{array}$ & $\begin{array}{l}0.012 \\
(0.37)\end{array}$ \\
\hline $\ln r l z b$ & $\begin{array}{l}-0.033 \\
(-1.25)\end{array}$ & $\begin{array}{l}-0.033 \\
(-1.25)\end{array}$ & $\begin{array}{l}-0.033 \\
(-1.25)\end{array}$ \\
\hline $\ln f d i$ & $\begin{array}{l}-0.025^{*} \\
(-1.94)\end{array}$ & $\begin{array}{l}-0.025^{*} \\
(-1.94)\end{array}$ & $\begin{array}{l}-0.025^{*} \\
(-1.94)\end{array}$ \\
\hline lnmykf & $\begin{array}{l}0.021^{*} \\
(1.94)\end{array}$ & $\begin{array}{l}0.021 \text { * } \\
(1.94)\end{array}$ & $\begin{array}{l}0.021^{*} \\
(1.94)\end{array}$ \\
\hline lnind & $\begin{array}{l}-0.110^{\text {** }} \\
(-2.58)\end{array}$ & $\begin{array}{l}-0.110 * * \\
(-2.58)\end{array}$ & $\begin{array}{l}-0.110^{* *} \\
(-2.58)\end{array}$ \\
\hline $\operatorname{lncsh}$ & $\begin{array}{l}-0.061 \\
(-0.46)\end{array}$ & $\begin{array}{l}-0.061 \\
(-0.46)\end{array}$ & $\begin{array}{l}-0.061 \\
(-0.46)\end{array}$ \\
\hline $\ln E_{i t} \cdot F\left(\ln D_{i t} \leq 3.7180\right)$ & $\begin{array}{l}0.425^{* * * *} \\
(31.96)\end{array}$ & $\begin{array}{l}0.425^{\text {**** }} \\
(31.96)\end{array}$ & $\begin{array}{l}0.425^{* * * *} \\
(31.96)\end{array}$ \\
\hline $\ln E_{i t} \cdot F\left(3.7180 \leq \ln D_{i t} \leq 4.7529\right)$ & $\begin{array}{l}0.349^{* * * *} \\
(37.11)\end{array}$ & $\begin{array}{l}0.349^{\text {**** }} \\
(37.11)\end{array}$ & $\begin{array}{l}0.349^{* * * *} \\
(37.11)\end{array}$ \\
\hline $\ln E_{i t} \cdot F\left(\ln D_{i t} \geq 4.7529\right)$ & $\begin{array}{l}0.255^{* * * *} \\
(20.47)\end{array}$ & $\begin{array}{l}0.255^{\text {**** }} \\
(20.47)\end{array}$ & $\begin{array}{l}0.255^{* * *} \\
(20.47)\end{array}$ \\
\hline Constant & $\begin{array}{l}-2.861 \\
(-1.62)\end{array}$ & $\begin{array}{l}-2.861 \\
(-1.62)\end{array}$ & $\begin{array}{l}-2.861 \\
(-1.62)\end{array}$ \\
\hline$R^{2}$ & 0.944 & 0.967 & 0.939 \\
\hline Observations & 210 & 210 & 210 \\
\hline
\end{tabular}

The values in brackets are $T$ values

* represents $P<0.1$; ** represents $P<0.05$; *** represents $P<0.01$ 
Table 15 Development level of the digital economy in different provinces

\begin{tabular}{|c|c|c|c|c|c|}
\hline $\ln D_{\mathrm{it}} \leq 3.7180$ & $\mathrm{~N}$ & $3.7180 \leq \ln D_{\mathrm{it}} \leq 4.7529$ & $\mathrm{~N}$ & $4.7529 \leq \ln D_{\mathrm{it}}$ & $\mathrm{N}$ \\
\hline $\begin{array}{l}\text { Shanxi (3.7078), Xinjiang (3.6794), Heilongjiang } \\
\text { (3.6198), Gansu (3.5227), Jilin (3.4973), Ningxia } \\
\text { (3.4665), Qinghai (3.4590), Tianjin (3.3501) }\end{array}$ & 8 & $\begin{array}{l}\text { Zhejiang (4.7060), Jiangsu (4.6791), Shandong (4.4431), } \\
\text { Shanghai (4.4293), Sichuan (4.2014), Hebei (4.0411), } \\
\text { Liaoning (4.0187), Henan (4.0181), Anhui (3.9570), } \\
\text { Hunan (3.9267), Chongqing (3.9242), Hainan } \\
\text { (3.8600), Hubei (3.8964), Shaanxi (3.8261), Guangxi } \\
\text { (3.8248), Inner Mongolia (3.8020), Yunnan (3.7923), } \\
\text { Jiangxi (3.7628), Guizhou (3.7180) }\end{array}$ & 19 & $\begin{array}{l}\text { Beijing (5.0693), } \\
\text { Fujian (5.0580), } \\
\text { Guangdong } \\
(4.7529)\end{array}$ & 3 \\
\hline
\end{tabular}

the digital economy. The digital economy provides more obvious "information and technology incentives" to enterprises and users. Driven by a higher level of the digital economy, companies are more willing to transform their energy structure and save energy. And the information integration effect of the digital economy has a more obvious effect on improving energy efficiency. Energy efficiency directly affects the amount of energy required to provide products and services so as to reduce energy consumption and curb the increase of carbon emissions. Moreover, the central and western regions are facing greater economic development pressure compared with the eastern region. Therefore, these two regions pay more attention to the short-term impact of energy consumption on economic growth and pay less attention to the development of digital economy and energy structure adjustment. Therefore, the regulatory effect of digital economy in the impact of energy structure on carbon emissions has not been effectively exerted.

The digital economy has a significant regulatory role in non-resource-based provinces but not significant in resourcebased provinces. The reason is that, on one hand, compared with non-resource-based provinces, resource-based provinces undertake the two important tasks of supplying production factors and maintaining economic growth. GDP-oriented performance concept drives local governments to use resources with comparative advantages to attract resource-based industries to gather in the region. But the traditional extractive industry as the pillar of economic development will make the development of emerging technologies subject to the dilemma of the "economy-environment" zero-sum game, causing resource-based provinces to ignore the development of environmentally friendly technologies. On the other hand, resource-based industries have a relatively great demand for production factors such as capital and labor and have strong "stickiness" (Liebowitz and Margolis 1995), which has a significant "crowding-out effect" on innovative enterprises. Thus, it is not conducive to promoting the regional technology level, and the development level of digital technology is low. Therefore, the positive regulatory role of the digital economy has not yet appeared.

\section{Discussion of threshold effect estimation results}

The nonlinear effect of energy structure on carbon emissions, with the digital economy as the threshold variable, is the further research of this paper based on the heterogeneity analysis of moderating effect. According to Table 14 , when $\ln \mathrm{D}_{\mathrm{it}} \leq$ 3.7180 , the level of the digital economy does not pass the threshold, and the positive effect of energy structure on carbon emissions is 0.425 ; when $3.7180 \leq \ln \mathrm{D}_{\mathrm{it}} \leq 4.7529$, the positive effect of energy structure on carbon emissions is 0.349 , which is $17.88 \%$ lower than that of regions without passing the threshold; when $\ln D_{i t} \geq 4.7529$, the impact of energy structure on carbon emissions is only 0.255 , which is $34.12 \%$ lower than that of regions without passing the threshold. Therefore, the digital economy is an important driving factor for carbon emission reduction, and only a high level of digital economy development quality can reduce the adverse impact of energy structure on carbon emissions. The higher the level of the digital economy, the less negative effect of the energy consumption structure dominated by coal on carbon emissions will be. In the role of the digital economy, energy consumption has brought economic growth, but the adverse output (carbon emissions) is lower than in places where the digital development level failed to pass the threshold. Therefore, the digital economy is a strong competitive force for a region to balance the "economic growth-environmental pollution" dilemma.

\section{Conclusions and implications}

Based on the extended STIRPAT model, this paper empirically tests the impact of energy structure and digital economy on carbon emissions in 30 provinces of China from 2011 to 2017 and discusses the heterogeneity of economic level and resource endowment. The static and dynamic regression results show that the energy structure has a significant driving effect on carbon emissions, and the conclusion is still robust after changing the explained variables. It is worth noting that this kind of influence has a greater impact on the central region of 
China, followed by the western region and the eastern region. In addition, the digital economy has a significant moderating effect. Specifically, the digital economy can play the role of energy conservation and emission reduction. With the development of the digital economy, the impact of coal-based energy structure on carbon emissions is gradually decreasing. This effect is more obvious in non-resource-based provinces and eastern China but not obvious in resource-based cities and central and western China. On the basis of the above analysis results, this paper gets the following enlightenment:

Combined with the regional characteristics, we believe that, as the key carbon emission regions with higher economic development level, the eastern and non-resource-based provinces should pay attention to the development of green technology, effectively use the advantages of local talents and capital, research and develop green technology and transform process flow, improve energy utilization efficiency, and promote the development of energy conservation and emission reduction technology. The central and resource-based provinces need to take into account the governance of input and output. On one hand, the central and resource-based provinces should abandon the traditional path of resource-based industries for growth, restrict the development of high energy consumption and high-carbon emission enterprises, and promote the transformation and upgrading of industrial structure. On the other hand, the government should improve the market mechanism design of carbon emission reduction and guide enterprises to pay attention to the application of green technology in the form of carbon tax and carbon emission right, so as to realize low-carbon development. The western region needs to focus on breaking through the bottleneck of photovoltaic, wind, solar, and other clean energy utilization, strive to realize the wide application of clean energy as soon as possible, and decarbonize production and life by means of energy structure transformation.

Digital economy includes digital industrialization and digital industry. Among them, digital industrialization is the foundation. According to the white paper on China's Digital Economy Development and Employment (2018), China's digital foundation is weak, and it still needs a process for China's manufacturing industry from automation and digitization to networking and intellectualization. Therefore, the government should guarantee the orderly progress of digital economy infrastructure construction by means of financial support, industrial support, investment, and financing inclination. In addition, the government should encourage social and economic entities to increase their understanding and application of digital technology, expand digital reform efforts, and promote the wide application of digital technology in the three major industries. Due to the unbalanced development level of digital economy among regions, digital knowledge and technology need to be widely popularized in less developed areas. In order to narrow the development gap of digital economy between regions, the government should build a platform for knowledge and technology communication and exchange among regions. Threshold effect shows that the higher the development level of digital economy, the more obvious the effect of emission reduction. This means that while promoting the popularization of digital knowledge and technology, innovation and breakthrough of digital technology still need to be placed in an important position. Finally, the healthy development of digital economy is inseparable from the effective supervision and management mechanism. In the process of the integration of digital economy and traditional industries, and the birth of new business state by digital economy, the government should also pay attention to the potential security risks of digital economy, so as to ensure that the application and promotion of digital economy can play an "enabling" role.

Code availability Source codes are available on request.

Author contribution Y.L.: Conceptualization, project administration, formal analysis, writing - review \& editing, data curation, writingoriginal draft. X.Y.: Writing - review \& editing, validation. Q.R.: Conceptualization, methodology, funding acquisition, supervision. H.W.: Conceptualization, methodology, funding acquisition, supervision. M.I.: Writing — original draft, writing — review \& editing, formal analysis. M.A.: Writing — review \& editing, writing — original draft.

Funding The authors acknowledge financial support from the Project of National Natural Science Foundation of China (71463057), the Project of Natural Science Foundation of Xinjiang Uygur Autonomous Region (2017D01C071), the key scientific research projects of universities in Xinjiang (XJEDU2019SI003), the Silk Road Foundation of Xinjiang University (JGSL18053), the second phase project of the School of Economics and Management of Xinjiang University (19JGPY001), and the graduate research and innovation project of Xinjiang University (XJ2019G005, XJ2020G020). The party central committee's XinjiangGovernance strategy theory and practice research key project (19ZJFLZ09) is also acknowledged. The usual disclaimer applies.

Data availability Not applicable.

\section{Declarations}

Ethical approval and consent to participate Not applicable.

Consent for publication Not applicable.

Conflict of interest The authors declare no competing interests.

\section{References}

Ahmad M, Zhao Z-Y, Irfan M, Mukeshimana MC (2019) Empirics on influencing mechanisms among energy, finance, trade, environment, and economic growth: a heterogeneous dynamic panel data analysis of China. Environ Sci Pollut Res 26(14):14148-14170

Ahmad M, Ahmed N, Jabeen M, Jabeen G, Qamar S, Chandio AA, Rehman A, Rauf A (2020) Empirics on heterogeneous links among 
urbanization, the intensity of electric power consumption, waterbased emissions, and economic progress in regional China. Environ Sci Pollut Res 27(31):38937-38950

Ahmad M, Chandio AA, Solangi YA, Shah SAA, Shahzad F, Rehman A, Jabeen G (2021) Dynamic interactive links among sustainable energy investment, air pollution, and sustainable development in regional China. Environ Sci Pollut Res 28(2):1502-1518

Alam MM, Murad MW (2020) The impacts of economic growth, trade openness and technological progress on renewable energy use in organization for economic co-operation and development countries. Renew Energy 145(Jan.):382-390

Anser MK, Ahmad M, Khan MA, Zaman K, Nassani AA, Askar SE, Abro MMQ, Kabbani A (2021) The role of information and communication technologies in mitigating carbon emissions: evidence from panel quantile regression. Environ Sci Pollut Res 28(17): 21065-21084

Antoci A, Galeotti M, Sordi S (2018) Environmental pollution as an engine of industrialization. Commun Nonlinear Sci Numer SimulEnvironmental pollution as engine of industrialization. Communications in Nonlinear Science and Numerical Simulation, $58,262-273$

Arellano M, Bond S (1991) Some tests of specification for panel data: Monte Carlo evidence and an application to employment equations. Rev Econ Stud 58(2):277-297

Aydin E, Brounen D, Kok N (2018) Information provision and energy consumption: evidence from a field experiment. Energy Econ 71: 403-410

Bhattacharya M, Rafiq S, Bhattacharya S (2015) The role of technology on the dynamics of coal consumption-economic growth: new evidence from China. Appl Energy 154:686-695

Birdsall N (1992) Another look at population and global warming. Research Papers in Economics, 1

Blundell R, Bond SR (1998) Initial conditions and moment restrictions in dynamic panel data models. J Econ 87(1):115-143

Cansino JM, Sánchez-Braza A, Rodríguez-Arévalo ML (2015) Driving forces of Spain's $\mathrm{CO}_{2}$ emissions: a LMDI decomposition approach. Renew Sust Energ Rev 48:749-759

Cao J, Law SH, Samad ARBA, Mohamad WNBW, Wang J, Yang X (2021) Impact of financial development and technological innovation on the volatility of green growth-evidence from China. Environ Sci Pollut Res:1-17

Chen Y (2020) Improving market performance in the digital economy. China Econ Rev 62:101482

Chen C, Pinar M, Stengos T (2020) Renewable energy consumption and economic growth nexus: evidence from a threshold model. Energy Policy 139:111295

Dietz T, Rosa EA (1994) Rethinking the environmental impacts of population, Affluence and Technology

Dogan E, Seker F (2016) Determinants of $\mathrm{CO}_{2}$ emissions in the European Union: the role of renewable and non-renewable energy. Renew Energy 94:429-439

Ehrlich PR, Holdren JP (1971) Impact of population growth. Obstet Gynecol Surv 26(11):769-771

Ertugrul HM, Cetin M, Seker F, Dogan E (2016) The impact of trade openness on global carbon dioxide emissions: evidence from the top ten emitters among developing countries. Ecol Indic 67:543-555

Exponential roadmap (2020) Exponential roadmap2030[EB/OL]. https:// exponentialroadmap.org/,2020-3

Feng Y, Wang X, Liang Z (2021a) How does environmental information disclosure affect economic development and haze pollution in Chinese cities? The mediating role of green technology innovation. Sci Total Environ 775:145811
Feng Y, Wang X, Liang Z, Hu S, Xie Y, Wu G (2021b) Effects of emission trading system on green total factor productivity in China: empirical evidence from a quasi-natural experiment. J Clean Prod 294:126262

Fouquet R (2016) Path dependence in energy systems and economic development. Nat Energy 1(8):16098

Gan T, Liang W, Yang H, Liao X (2020) The effects of haze pollution on economic development and spatial distribution of PM2.5 in haze pollution. Urbanization as a mediating variable. J Clean Prod 266: 121880

Guo X, Ge J (2004) Simulation study on integrated development system of "resources economy environment" in West to East gas transmission corridor. Journal of system simulation 11:2533-2537 (in Chinese)

Guozhi L, Zongzhi L, Ming Z (2011) Provincial comparison and factor decomposition of energy carbon emissions in eastern China. Contemporary economic management 33(10):48-52 (in Chinese)

Hao X, Deng F (2019) The marginal and double threshold effects of regional innovation on energy consumption structure: evidence from resource-based regions in China. Energy Policy 131:144-154

Hao Y, Ba N, Ren S, Wu H (2021a) How does international technology spillover affect China's carbon emissions? A new perspective through intellectual property protection. Sustainable Production and Consumption 25:577-590

Hao Y, Gao S, Guo Y, Gai Z, Wu H (2021b) Measuring the nexus between economic development and environmental quality based on environmental Kuznets curve: a comparative study between China and Germany for the period of 2000-2017. Environment, Development and Sustainability, 1-26

Heiskanen E, Jalas M, Timonen P (2005) Reducing the natural resource intensity of private and organisational consumption: the potential of ICT and service innovations. Progress in Industrial Ecology, An International Journal 2:453-474

Hsiao C (1986) Analysis of Panel Data, Vol. 11 of Econometric Society Monographs. Cambridge University Press, New York.

Huang C, Zhang X, Liu K (2021) Effects of human capital structural evolution on carbon emissions intensity in China: a dual perspective of spatial heterogeneity and nonlinear linkages. Renew Sust Energ Rev 135:110258

Irfan M, Elavarasan RM, Hao Y, Feng M, Sailan D (2021) An assessment of consumers' willingness to utilize solar energy in China: endusers' perspective. J Clean Prod 292:126008

Jin L, Wu H (2013) Regional heterogeneity of China's carbon emissions and countermeasures. Econ Manag 27(11):83-87 (in Chinese)

Junior JAG, Busso CM, Gobbo SCO, Carreão H (2018) Making the links among environmental protection, process safety, and industry 4.0. Process Saf Environ Prot 117:372-382

Kjaer LL, Pigosso DCA, McAloone TC, Birkved M (2018) Guidelines for evaluating the environmental performance of Product/ServiceSystems through life cycle assessment. J Clean Prod 190:666-678

Knapp T, Mookerjee R (1996) Population growth and global $\mathrm{CO}_{2}$ emissions: a secular perspective. Energy Policy 24(1):31-37

Li Q, Wang M, Xiangli L (2021a) Do government subsidies promote new-energy firms' innovation? Evidence from dynamic and threshold models. J Clean Prod 286:124992

Li R, Wang Q, Liu Y, Jiang R (2021b) Per-capita carbon emissions in 147 countries: effects of economic, energy, social, and trade structural changes. Sustainable Production and Consumption

Liebowitz SJ, Margolis SE (1995) Path dependence, lock-in, and history. J Law Econ Org 11(1):205-226 
Liu Y, Zhou Y, Wu W (2015) Assessing the impact of population, income and technology on energy consumption and industrial pollutant emissions in China. Appl Energy 155:904-917

Liu J, Yuanyi Y, Zhang S (2020) Research on China's digital economic measurement and driving factors. Shanghai Economic Research 06: 81-96 (in Chinese)

Liu J, Li S, Ji Q (2021) Regional differences and driving factors analysis of carbon emission intensity from transport sector in China. Energy 224:120178

Maheshwari B, Pinto U, Akbar S, Fahey P (2020) Is urbanisation also the culprit of climate change? - evidence from Australian cities. Urban Clim 31:100581

Mahmood H, Alkhateeb TTY, Furqan M (2020) Industrialization, urbanization and $\mathrm{CO}_{2}$ emissions in Saudi Arabia: asymmetry analysis. Energy Rep 6:1553-1560

Mao J (2019) Government behavior, environmental regulation and regional technological innovation - an analysis based on regional heterogeneity and path mechanism. Journal of Shanxi University of Finance and Economics 41(05):16-27 (in Chinese)

Miller P, Wilsdon J (2001) Digital futures - an agenda for a sustainable digital economy. Corp Environ Strateg 8(3):275-280

Narayan S, Doytch N (2017) An investigation of renewable and nonrenewable energy consumption and economic growth nexus using industrial and residential energy consumption. Energy Econ 68: $160-176$

Nguyen KH, Kakinaka M (2019) Renewable energy consumption, carbon emissions, and development stages: some evidence from panel cointegration analysis. Renew Energy 132:1049-1057

Ozturk I, Acaravci A (2010) $\mathrm{CO}_{2}$ emissions, energy consumption and economic growth in Turkey. Renew Sust Energ Rev 14(9):3220 3225

Palencia JCG, Furubayashi T, Nakata T (2013) Analysis of $\mathrm{CO}_{2}$ emissions reduction potential in secondary production and semifabrication of non-ferrous metals. Energy Policy 52:328-341

Petrović P, Lobanov MM (2020) The impact of R\&D expenditures on $\mathrm{CO}_{2}$ emissions: evidence from sixteen OECD countries. J Clean Prod 248:119187

Rademaeker ED, Suter G, Pasman HJ, Fabiano B (2014) A review of the past, present and future of the European loss prevention and safety promotion in the process industries. Process Saf Environ Prot 92(4): 280-291

Rehman A, Rauf A, Ahmad M, Chandio AA, Deyuan Z (2019) The effect of carbon dioxide emission and the consumption of electrical energy, fossil fuel energy, and renewable energy, on economic performance: evidence from Pakistan. Environ Sci Pollut Res 26(21): 21760-21773

Rehman A, Ma H, Ozturk I, Ahmad M, Rauf A, Irfan M (2020) Another outlook to sector-level energy consumption in Pakistan from dominant energy sources and correlation with economic growth. Environ Sci Pollut Res:1-16

Rehman A, Ma H, Ahmad M, Ozturk I, Ișık C (2021a) Estimating the connection of information technology, foreign direct investment, trade, renewable energy and economic progress in Pakistan: evidence from ARDL approach and cointegrating regression analysis. Environ Sci Pollut Res:1-13

Rehman A, Ma H, Chishti MZ, Ozturk I, Irfan M, Ahmad M (2021b) Asymmetric investigation to track the effect of urbanization, energy utilization, fossil fuel energy and $\mathrm{CO}_{2}$ emission on economic efficiency in China: another outlook. Environ Sci Pollut Res 28(14): $17319-17330$
Ren S, Hao Y, Xu L, Wu H, Ba N (2021) Digitalization and energy: how does internet development affect China's energy consumption? Energy Econ 98:105220

Shafiei S, Salim RA (2014) Non-renewable and renewable energy consumption and $\mathrm{CO}_{2}$ emissions in OECD countries: a comparative analysis. Energy Policy 66:547-556

Shuai C, Shen L, Jiao L, Wu Y, Tan Y (2017) Identifying key impact factors on carbon emission: evidences from panel and time-series data of 125 countries from 1990 to 2011. Appl Energy 187:310-325

Soares JB, Tolmasquim MT (2000) Energy efficiency and reduction of $\mathrm{CO}_{2}$ emissions through 2015: the Brazilian cement industry. Mitig Adapt Strateg Glob Chang 5(3):297-318

Song H, Peng D (2019) Factor endowment structure, biased technological progress and total factor productivity growth: an empirical study based on stochastic frontier function of regional heterogeneity. Jiangxi Social Sciences, 39(09):47-59+254-255 (in Chinese)

Su X, Yang X, Zhang J, Yan J, Zhao J, Shen J, Ran Q (2021) Analysis of the impacts of economic growth targets and marketization on energy efficiency: evidence from China. Sustainability 13(8):4393

Tian C, Li L, Yang H, Shang H, Jia N, Dong W, Jiang C, Zhao G (2006) Study on environmental synergy of West to East Gas Transmission Project. Environ Sci Res 03:122-127 (in Chinese)

Usman A, Ozturk I, Hassan A, Zafar SM, Ullah S (2021) The effect of ICT on energy consumption and economic growth in South Asian economies: an empirical analysis. Telematics Inform 58:101537

$\mathrm{Vu}$ KM (2011) ICT as a source of economic growth in the information age: empirical evidence from the 1996-2005 period. Telecommun Policy 35(4):357-372

Wang K, Wu M, Sun Y, Shi X, Sun A, Zhang P (2019) Resource abundance, industrial structure, and regional carbon emissions efficiency in China. Res Policy 60:203-214

Wang B, He L, Yuan X-C, Sun Z-M, Liu P (2021) Carbon emissions of coal supply chain: an innovative perspective from physical to economic. J Clean Prod 295:126377

Watts N, Amann M, Arnell N, Ayeb-Karlsson S, Beagley J, Belesova K et al (2021) The 2020 report of The Lancet Countdown on health and climate change: responding to converging crises. Lancet 397(10269):129-170

Wu Y, Zhu Q, Zhu B (2018) Comparisons of decoupling trends of global economic growth and energy consumption between developed and developing countries. Energy Policy 116:30-38

Wu H, Hao Y, Ren S (2020) How do environmental regulation and environmental decentralization affect green total factor energy efficiency: evidence from China. Energy Econ 91:104880

Wu W, Zhang T, Xie X, Huang Z (2021) Regional low carbon development pathways for the Yangtze River Delta region in China. Energy Policy 151:112172

Wu H, Xia Y, Yang X, Hao Y, Ren S (2021a) Does environmental pollution promote China's crime rate? A new perspective through government official corruption. Struct Chang Econ Dyn 57:292-307

Wu H, Hao Y, Ren S, Yang X, Xie G (2021b) Does internet development improve green total factor energy efficiency? Evidence from China. Energy Policy 153:112247

Xu B, Chen Y, Shen X (2019) The clean energy development, carbon dioxide emission reduction and regional economic growth. Econ Res 54(07):188-202 (in Chinese)

Yan Y, Wang R, Zheng X, Zhao Z (2020) Carbon endowment and tradeembodied carbon emissions in global value chains: evidence from China. Appl Energy 277:115592

Yang, Zhongshan., \& Wei, Xiaoxue. (2018) Total factor energy efficiency of the regions along the belt and road-measurements, 
decomposition and influence factors analysis. China Environ Sci 38(11):4384-4392 (in Chinese)

Yang X, Wu H, Ren S, Ran Q, Zhang J (2021a) Does the development of the internet contribute to air pollution control in China? Mechanism discussion and empirical test. Struct Chang Econ Dyn 56:207-224

Yang X, Zhang J, Ren S, Ran Q (2021b) Can the new energy demonstration city policy reduce environmental pollution? Evidence from a quasi-natural experiment in China. J Clean Prod 287:125015

Yong W, Ying W (2019) Feasibility and optimal path for China to achieve the goal of dual control of carbon emission reductionfrom the perspective of energy structure optimization. China Environmental Science and Technology 39(10):4444-4455 (in Chinese)

Yu S, Zheng S, Li X (2018) The achievement of the carbon emissions peak in China: the role of energy consumption structure optimization. Energy Econ 74:693-707

Yu J, Li J, Zhang W (2019) Identification and classification of resourcebased cities in China. J Geogr Sci 29(8):1300-1314
Yuan S, Musibau HO, Genç SY, Shaheen R, Ameen A, Tan Z (2021) Digitalization of economy is the key factor behind fourth industrial revolution: how G7 countries are overcoming with the financing issues? Technol Forecast Soc Chang 165:120533

Zhang C, Lin Y (2012) Panel estimation for urbanization, energy consumption and $\mathrm{CO}_{2}$ emissions: a regional analysis in China. Energy Policy 49:488-498

Wu W, Zhang T, Xie X, Huang Z (2021) Regional low carbon development pathways for the Yangtze River Delta region in China. Energy Policy 151:112172

Allam Z, Jones DS (2021) Future (post-COVID) digital, smart and sustainable cities in the wake of 6G: Digital twins, immersive realities and new urban economies. Land Use Policy, 101(101):105201

Publisher's note Springer Nature remains neutral with regard to jurisdictional claims in published maps and institutional affiliations. 